\title{
Aid Project Proliferation and Absorptive Capacity
}

\section{David Roodman*}

January 2006

\begin{abstract}
Much public discussion about foreign aid has focused on whether and how to increase its quantity. But recently aid quality has come to the fore, by which is meant the efficiency of the aid delivery process. This paper focuses on one process problem, the proliferation of aid projects and the associated administrative burden for recipients. It models aid delivery as a set of production activities (projects) with two inputs - the donor's aid and a recipient-side resource - and two outputs - development and 'throughput', which represents the private benefits of implementing projects, from kickbacks to career rewards for disbursing. The donor's allocation of aid across projects is taken as exogenous while the recipient's allocation of its resource is modelled and subject to a budget constraint. Unless the recipient cares purely about development, an aid increase can reduce development in some circumstances. Sunk costs, representing for the recipient the administrative burden of donor meetings and reports, are introduced. Using data on the distribution of projects by size and country, simulations of aid increases are run in order to examine how the project distribution evolves, how the recipient's resource allocation responds, and how this affects development if the recipient is not a pure development optimizer. A threshold is revealed beyond which marginal aid effectiveness drops sharply. It occurs when development maximization calls for the recipient to withdraw from some donor-backed projects, but the recipient does not, for the sake of throughput. Donors can push back this threshold by moving to larger projects if there are scale economies in aid projects.
\end{abstract}

Keywords: foreign aid, absorptive capacity, project proliferation

JEL classification: F35, O12, O19, O20

Copyright (C) UNU-WIDER 2006

* Center for Global Development, Washington, DC, email: droodman@cgdev.org

This study is a revised version of the paper presented at the 16-17 September 2005 project meeting on Development Aid: A Fresh Look, directed by George Mavrotas and Mark McGillivray.

UNU-WIDER acknowledges the financial contributions to the research programme by the governments of Denmark (Royal Ministry of Foreign Affairs), Finland (Ministry for Foreign Affairs), Norway (Royal Ministry of Foreign Affairs), Sweden (Swedish International Development Cooperation Agency-Sida) and the United Kingdom (Department for International Development).

ISSN 1810-2611 ISBN 92-9190-770-7 (internet version) 
The World Institute for Development Economics Research (WIDER) was established by the United Nations University (UNU) as its first research and training centre and started work in Helsinki, Finland in 1985. The Institute undertakes applied research and policy analysis on structural changes affecting the developing and transitional economies, provides a forum for the advocacy of policies leading to robust, equitable and environmentally sustainable growth, and promotes capacity strengthening and training in the field of economic and social policy making. Work is carried out by staff researchers and visiting scholars in Helsinki and through networks of collaborating scholars and institutions around the world.

www.wider.unu.edu

publications@wider.unu.edu

UNU World Institute for Development Economics Research (UNU-WIDER)

Katajanokanlaituri 6 B, 00160 Helsinki, Finland

Camera-ready typescript prepared by T:mi LHR Editorial and Secretarial Assistance

The views expressed in this publication are those of the author(s). Publication does not imply endorsement by the Institute or the United Nations University, nor by the programme/project sponsors, of any of the views expressed. 
Public discussion about foreign aid has long focused on the question of 'how much?' Since the early 1960s, there have been observers who called on rich countries to give 0.7 per cent of their GDP in aid (Clemens and Moss 2005). The proposed International Financing Facility would double aid in the short run. The UN Secretary-General's report, Investing in Development, calls for a tripling (UNDP 2005b).

Recently, however, aid quality has come to the fore in the public policy debate (Roodman 2005; UNDP 2005a; World Bank 2005; ActionAid 2005). Quality can be defined as the capacity, per dollar, for aid to increase development and reduce poverty. In practice, it has much to do with inefficiencies in the aid delivery process. And while one might debate whether aid quantity ought to rise in any given country, it is hard to argue that aid quality should not. Under the rubric of 'aid quality' come a number of themes: untying (dropping requirements that aid be accepted in kind or spent on donor-country goods and services); selectivity (for countries deemed more deserving and propitious as recipients); harmonization (of donors' procurement, reporting, and other requirements); alignment (with the recipient's own goals and plans); coordination (among donors to prevent duplicative efforts); and proliferation (of many small aid projects). In February 2003, representatives of 40 donor agencies signed the Rome Declaration calling for greater harmonization and alignment of aid, among other things. They reconvened in 2005 and issued the Paris Declaration, which expands the agenda to include untying and coordination.

This paper focuses on the problem of project proliferation, which is thought to impose great administrative burdens on some recipient governments. Using available data on aid activities, it first shows why one should worry that there are too many aid projects. It then defines a model in which a recipient's resources combine with aid in a set of projects to produce development. If donor and recipient do not both maximize development, but rather such things as meeting per diems and the career benefits of disbursement for aid officials, collectively labelled 'throughput', then it is possible for an aid increase to reduce development.

The paper then moves to the continuous setting, positing a suite of projects lognormally distributed by aid size. Sunk costs are also introduced to represent the recipient-side cost of donor meetings and quarterly reports. A simulation is then run to illustrate how the strategy that the recipient uses to allocate its resource across projects varies as total aid expands. The simulation also shows how this affects development. It is partially calibrated using detailed data on aid projects covering most donor and recipient countries. It turns out that there is a strong relationship between the total amount of aid a country gets and the distribution of its projects by size. When total aid increases beyond a certain point and projects proliferate in the way suggested by the data, the effective marginal product of aid, factoring in recipient behaviour, declines sharply, and can again go negative. Thus the model hints at the existence of thresholds beyond which aid becomes much less effective in practice; it gives rise to a notion of absorptive capacity. 


\section{Background and motivation}

According to Morrs (1984), during the 1950s and 1960s most foreign assistance took the form of programme aid, by which he means large infrastructure investments as well as packages of sector support, such as for agriculture, that include finance, commodities, and technical assistance. However, as concerns grew about the effectiveness of aid, legislatures demanded more evidence of results. By the 1970s this led to far greater use of project aid, which 'entails a more specific statement of objectives and means'. The multiplication of aid projects with more narrowly and precisely defined goals and more measurable outcomes was compounded by the multiplication of donors after Western European nations and Japan recovered from the Second World War. Morrs (1984: 46570) identifies several troubling consequences, including lack of coordination on the donor side and lack of ownership on the recipient side. In addition is the administrative burden associated with the sheer number of projects:

[E]fforts to implement the large number of discrete, donor-financed projects, each with its own specific objectives and reporting requirements, use up far more time and effort than is appropriate.

There is no sign that the administrative burden has lessened in the 20 years since Morrs wrote. Van de Walle and Johnston (1996) report roughly 60 active donors and 600 ongoing projects each in Kenya and Zambia in the mid-1980s, and some 40 donors and 2,000 aid projects in Tanzania in the mid-1990s. Starting from a hypothetical project count of 600 , they suggest that recipient governments typically file 2,400 quarterly reports to donors and host 1,000 'missions' from donor officials to monitor project activities. These two numbers appear to have been picked up by a speechwriter for former World Bank President James Wolfensohn and misinterpreted as a fact about Tanzania, leading to the urban legend that Tanzania files 2,400 reports and hosts 1,000 missions each year. If anything, the figures are substantial underestimates for Tanzania.

In fact, in the spring of 2003, the Tanzanian ministry of finance took a striking step to manage the administrative burdens associated with aid. It announced that the period April-August each year would be a 'quiet time' during which only the most urgent donor missions would be received. Tanzanian officials were to use this time to prepare the central government budget. In addition, as a sort of naming-and-shaming exercise, the government began posting on the Web a cumulative list of major meetings with donors. 1

Data suggest that the project proliferation problem extends beyond Tanzania and might be worsening. Like most important concepts, that of a 'project' is complex on close examination and hard to define precisely, so any effort to count them must begin with definitions. Is an organized effort to build ten schools ten projects or one? Where does one draw the line between large road-building projects and 'programmes' of support to the transportation sector? The definition used in this paper is partly principled, partly pragmatic, driven by the structure of available data. The best relevant and available data source is the Creditor Report System (CRS) database maintained by the Development Assistance Committee (DAC) in Paris. CRS Table 1 contains detailed information on individual aid commitments by bilateral and multilateral donors to fund what the CRS

1 See www.tzdac.or.tz/Mission\%20calendar.doc . 
reporting directives refer to as 'aid activities' (DAC 2002). 2 The CRS guidelines for donors reporting to the database define an aid activity only to this extent:

An aid activity can take many forms. It could be a project or a programme, a cash transfer or delivery of goods, a training course or a research project, a debt relief operation or a contribution to an NGO (DAC 2002).

The data begin in 1973. Despite the 'creditor' in its name, the database covers both grant and loan commitments, including non-concessional ones, and even a few equity investments.

With respect to this dataset, a 'project' is defined here as an entry in CRS Table 1:

- that is not an equity investment;

- that fits the definition of overseas development assistance, meaning that it is a grant or adequately concessional loan for a development purpose;

- whose recipient is identified as a specific country, as opposed to, say, 'Africa unspecified';

- is not identified as being for administrative costs or support for nongovernmental organizations;

- $\quad$ is not identified as being emergency aid.

Somewhat confusingly, this definition includes Sector-Wide Action Programmes and budget support, which Morss calls programme aid. These are in effect very large projects, assuming commitments to them are in fact large in dollar terms. It seems appropriate to include them since excluding programme aid from the data (to the extent possible with a CRS coding system not designed for the purpose) could paint a misleading picture of how much individual donors tend to proliferate their overall aid portfolios.

Table 1 shows that the number of projects in the database according to this definition nearly tripled between 1995 and 2003. However, better reporting-more donors providing data, and on larger fractions of their portfolios - may account for the bulk of this increase. For this reason, comparisons based on cross-sections of the CRS database may be more meaningful than those based on time series. Table 2, therefore, reports the top-ten recipients of project commitments during 2001-03. It aggregates over three years on the idea that this proxies better for ongoing activities in 2003: commitments tend to lead to disbursements and project operations over several years. 3 Table 2 shows that most of the countries with high project counts are either very large or very poor.

2 CRS Table 5, which begins much more recently, has data on disbursement rather than commitments. This might seem more relevant since not all commitments are realized. But the reporting concept for this table is the financial transaction rather than the aid activity, and there can be many transactions per activity

3 Examination of extracts from the World Bank Development Gateway's Accessible Information on Development Activities (AiDA) database, suggested this value for average project duration. The AiDA database draws on the CRS and other sources, and contains project start and stop dates for some entries, unlike the CRS. However, it is inferior in other respects for the purposes of this study. 
Scholarly interest in proliferation also appears to be rising. Acharya, de Lima, and Moore (2004) develop indexes of donors' tendency to proliferate (disperse) aid among recipients, and of the tendency of recipients' aid to be fragmented among many donors. They find that the donors that are the greatest proliferators are especially likely to aid the countries with the greatest aid fragmentation.

Knack and Rahman (2004) investigate an index of fragmentation similar to that of Acharya, de Lima, and Moore as a determinant of another variable of interest. In their model, donors compete with each other and the government for the scarce resource of skilled nationals. Hiring a skilled professional away from the government reduces the quality of public governance, which is a public-good input to all aid projects. The lower a donor's share in the recipient's aid 'market', the less it internalizes this cost, and the more incentive it has to poach the best people from the government. Knack and Rahman thus predict - and appear to confirm empirically - that aid fragementation reduces the quality of public bureaucracy.

Table 1

Number of reported project commitments, 1995-2003, all donors

\begin{tabular}{ll}
\hline Year & Number \\
\hline 1995 & 10,327 \\
1996 & 10,626 \\
1997 & 10,310 \\
1998 & 14,790 \\
1999 & 20,692 \\
2000 & 20,847 \\
2001 & 28,739 \\
2002 & 25,716 \\
2003 & 27,876 \\
\hline
\end{tabular}

Source: Author's calculations, based on DAC (2005).

Table 2

Number of reported project commitments, 2001-03, top ten recipients

\begin{tabular}{lr}
\hline Country & Number \\
\hline Mozambique & 1,921 \\
India & 1,910 \\
China & 1,885 \\
Russia & 1,721 \\
Ethiopia & 1,677 \\
Indonesia & 1,639 \\
Vietnam & 1,609 \\
Tanzania & 1,528 \\
Serbia \& Montenegro & 1,497 \\
South Africa & 1,466 \\
\hline
\end{tabular}

Source: Author's calculations, based on DAC (2005). 
Both of these contributions relate to the proliferation of donors, not projects. Though donor and project proliferation no doubt go hand in hand, they are distinct notions. Countries with few donors can have many projects, and vice versa. The present study, therefore, focuses on project proliferation and illustrates how it can limit the ability of recipient countries to absorb aid effectively.

Thus another, and richer, literature is also relevant. According to a review in Clemens and Radelet (2003), a number of studies have attempted to measure absorptive capacity for aid via inclusion of linear and quadratic aid terms in growth regressions (Hadjimichael et al. 1995; Durbarry, Gemmell, and Greenaway 1998; Hansen and Tarp 2000, 2001; Hansen 2001; Lensink and White 2001; Collier and Dollar 2002; Dalgaard, Hansen, and Tarp 2002; Clemens, Radelet, and Bhavnani 2004). According to Clemens and Radelet, the implied turning points in the marginal impact of aid range from 15 per cent to 45 per cent of recipient GDP. A number of pathways have been suggested that would cause the marginal productivity of aid to fall and even go negative as aid increases. Aid may cause recipients to reduce tax effort. It may distort domestic political economy. It can siphon the best people away from government, as in Knack and Rahman. It causes Dutch Disease. Finally, it may encounter bottlenecks in recipient administration. The poorer the country, the weaker public institutions tend to be. And donor practices - heavy demands for meetings and reports, incompatible fiscal years and reporting requirements and so on-exacerbate these problems.

\section{A microeconomic model of aid projects}

The model presented here depicts the aid process as a set of production activities, one per project, with identical technologies. The key ideas in the model are:

- $\quad$ There is one donor and one recipient;

Aid projects have two inputs - aid and a recipient-side resource that can be thought of as spending on capital or recurring costs or the time of officials in recipient ministries;

- The donor's portfolio of projects is taken as exogenously determined;

- The recipient has a fixed budget for its resource, which it is free to allocate among aid projects to maximize its utility;

- Aid projects have two outputs too. One is 'development', which can be thought of as growth and poverty reduction. The other is 'throughput' and is meant to capture the more direct benefits of aid projects to the officials involved. On the donor side, this may encompass the political dynamic of aid tying and the career benefits of being associated with disbursing projects. On the recipient side, it may include similar professional benefits, as well as the high salaries that can come with working with donors, 'sitting fees' for going to meetings, travel, per diems, and so on. On both sides, it could also reflect dynamics of corruption;

- Each aid project produces its two outputs - development and throughputsimultaneously. Throughput and development generally rise or fall together. 
- $\quad$ Outputs are additive. If two projects would by themselves each produce one unit of development, then together they produce two.

- In general, both donor and recipient care about both development and throughput, but can weigh them differently.

- The model allows for sunk costs on the recipient side-investments in hosting meetings, filing reports, etc., that do not directly contribute to production but are required for aid to flow.

This section first describes the model in generality, then provides some more intuitive examples.

\subsection{A general model}

To formalize, write the development and throughput technologies as:

$$
\begin{aligned}
& D_{i}=D_{i}\left(A_{i}, R_{i}\right) \\
& B_{i}=B_{i}\left(A_{i}, R_{i}\right)
\end{aligned}
$$

where $i$ indexes projects. $D_{i}$ is development, $B_{i}$ is 'throughput' as a side-benefit, $A_{i}$ is aid quantity going into the project, and $R_{i}$ is the recipient-side resource. $A_{i}$ will also be called the 'size' of project $i$. To keep the notation compact, draw the equations together into vector-valued functions $\mathbf{D}(\mathbf{A}, \mathbf{R})$ and $\mathbf{B}(\mathbf{A}, \mathbf{R})$. Also, let $D=\sum D_{i}$ (total development produced) and define analogous symbols for the $B_{i}, R_{i}$, and $A_{i}$ (except that we will treat $R=\sum R_{i}$ as a binding budget constraint rather than a definition). We assume $\mathbf{A}, \mathbf{R} \geq \mathbf{0}$ - inputs are never negative.

The recipient's utility is $u_{R}(D, B)$ and the donor's, $u_{A}(D, B)$. Thus, both utilities depend only on the simple sums of the two kinds of outputs from individual projects. The recipient's problem, given the donor's aid allocation $\mathbf{A}$ and the recipient resource budget $R$, is:

$$
\begin{aligned}
& \max _{\mathbf{R}} u_{R}(D, B) \\
& \text { such that } \mathbf{l}^{\prime} \mathbf{R} \leq R \text { and } \mathbf{R} \geq 0
\end{aligned}
$$

where $\mathbf{\imath}$ is a column of 1 's. If $u_{R}$ satisfies the appropriate regularity conditions when considered as a function of $\mathbf{A}$ and $\mathbf{R}$, we can analyse this problem using a Lagrangian:

$$
\mathrm{L}(\lambda, \mathbf{R})=u_{R}\left(\sum D_{i}\left(A_{i}, R_{i}\right), \sum B_{i}\left(A_{i}, R_{i}\right)\right)-\lambda\left(\mathbf{t}^{\prime} \mathbf{R}-R\right) .
$$

Imposing $\nabla L=0$ yields the first-order conditions for a maximum:

$$
\begin{aligned}
& \mathbf{l}^{\prime} \mathbf{R}=R \\
& \left(\nabla_{\mathbf{R}} u_{R}\right)^{\prime}=\lambda \mathbf{l}
\end{aligned}
$$


where $\nabla_{\mathbf{R}}$ is the gradient operator with respect to $\mathbf{R}$. In words, the recipient consumes its budget and allocates so that the marginal utility of its resource is equalized across projects to $\lambda$. The second-order condition is that

$$
\nabla^{2} \mathbf{L}=\left[\begin{array}{cc}
0 & -\mathbf{l}^{\prime} \\
-\mathbf{l} & \nabla_{\mathbf{R}}^{2} u_{R}
\end{array}\right]
$$

is negative semi-definite.

To describe the dynamics as $\mathbf{A}$ varies, let $\hat{\mathbf{R}}(\mathbf{A})$ be the vector-valued 'indirect demand function' that maps the donor's allocation of aid among projects to the (optimizing) recipient's allocations of its resource. Define the 'indirect supply functions' and indirect utility functions

$$
\begin{aligned}
& \hat{\mathbf{D}}(\mathbf{A})=\mathbf{D}(\mathbf{A}, \hat{\mathbf{R}}(\mathbf{A})) \\
& \hat{\mathbf{B}}(\mathbf{A})=\mathbf{B}(\mathbf{A}, \hat{\mathbf{R}}(\mathbf{A})) \\
& \hat{u}_{R}(\mathbf{A})=u_{R}(\hat{\mathbf{D}}(\mathbf{A}), \hat{\mathbf{B}}(\mathbf{A})) \\
& \hat{u}_{A}(\mathbf{A})=u_{A}(\hat{\mathbf{D}}(\mathbf{A})) .
\end{aligned}
$$

These describe how output of development and throughput and the utility derived from them change as the donor varies its allocation of aid among projects and the recipient adapts its own allocation. Let $\hat{D}_{i}(\mathbf{A})$ and $\hat{B}_{i}(\mathbf{A})$ be the $i$ th components of $\hat{\mathbf{D}}(\mathbf{A})$ and $\hat{\mathbf{B}}(\mathbf{A})$, and $\hat{D}(\mathbf{A})$ and $\hat{B}(\mathbf{A})$ be the sums of these components, or 'total indirect supply functions'. These give total development and throughput for a given donor portfolio of projects of various sizes, assuming optimizing behaviour on the part of the recipient. All these variables actually depend on the recipient resource budget, $R$, too, but we suppress this argument for clarity. A vector of central interest is the gradient $\nabla \hat{D}$, that is, the derivative of total development with respect to the donor's allocation of aid across projects. The chain rule gives

$$
\nabla \hat{D}=\nabla_{\mathbf{A}} D+\nabla_{\mathbf{R}} D \cdot \nabla \hat{\mathbf{R}}
$$

One special case is worth noting. If the recipient is 'purely developmentalist', i.e., $u_{R}=D$, then $\nabla_{\mathbf{R}} D=\nabla_{\mathbf{R}} u_{\mathbf{R}}$, which by the first-order condition is just $\lambda_{\mathbf{l}}$ 'because the marginal development impact of the recipient's resource is equalized across projects. If $R$ is fixed, then the elements of $\nabla \hat{\mathbf{R}}$ sum to zero, meaning that $\nabla \hat{\mathbf{R}}$ is orthogonal to $\lambda \mathbf{r}^{\prime}$. As a result, the second term of (1) drops out:

$$
\nabla \hat{D}=\nabla_{\mathbf{A}} D
$$

If the recipient is a development-optimizer, then the marginal impact of a change in aid, factoring in how the recipient will reallocate its own resources at the margin, equals the marginal impact that would occur if the recipient made no reallocation. Although the recipient may in fact reallocate its resource at this margin, it has no effect on development, since at the margin the development impact of its resource is equalized across projects. This is an example of the Envelope Theorem (Varian 1992). 


\subsection{Examples}

We will consider two pairs of examples. In the first pair, the recipient is purely developmentalist, as in (2). In the second pair, it values throughput only.

Example 1: The recipient is purely developmentalist and the donor increases aid to one project.

There are two projects. Production of both development and throughput is CobbDouglas, with constant returns to scale in the case of throughput. Let

$$
\begin{gathered}
D_{i}=A_{i}^{\alpha_{D}} R_{i}^{\rho_{D}} \\
B_{i}=A_{i}^{\alpha_{B}} R_{i}^{\rho_{B}} \\
u_{R}(D, B)=D \\
0<\alpha_{D}, \rho_{D}, \alpha_{B}, \rho_{B} \leq 1 \\
\alpha_{B}+\rho_{B}=1 .
\end{gathered}
$$

Working with the Lagrangian, the first-order conditions for the recipient's optimum work out to

$$
\begin{gathered}
\rho_{D} A_{1}^{\alpha_{D}} R_{1}^{\rho_{D}-1}=\rho_{D} A_{2}^{\alpha_{D}} R_{2}^{\rho_{D}-1}=\lambda \\
R_{1}+R_{2}=R
\end{gathered}
$$

and have the solution

$$
\hat{R}_{i}=\frac{R}{A_{1}^{\gamma_{D}}+A_{2}^{\gamma_{D}}} A_{i}^{\gamma_{D}}
$$

where

$$
\gamma_{D}=\frac{\alpha_{D}}{1-\rho_{D}}
$$

Notice that $\gamma_{D}$ is 1 exactly when there are constant returns to scale in development $\left(\alpha_{D}+\rho_{D}=1\right)$ and greater (less) than 1 when there are economies (diseconomies) of scale. Because the $A_{i}^{\gamma_{D}}$ term in (3) is the only one that varies with $i$, it shapes the allocation: when there are economies of scale, the recipient allocates its resources more than proportionally to the projects with larger aid budgets, but does the opposite if there are scale diseconomies. When there are constant returns to scale in development, the recipient allocates its resource in direct proportion to the aid funding for each project.

We now examine how the production of development varies when the donor increases aid to project 1 while holding aid to project 2 fixed. Following (1), the quantity of interest is

$$
\frac{\partial \hat{D}}{\partial A_{1}}=\frac{\partial D_{1}}{\partial A_{1}}+\frac{\partial D_{1}}{\partial R_{1}} \frac{\partial \hat{R}_{1}}{\partial A_{1}}+\frac{\partial D_{2}}{\partial R_{2}} \frac{\partial \hat{R}_{2}}{\partial A_{1}} .
$$


This says that the aid increase affects development in three ways: directly, through increasing the output from project 1 , and indirectly, by causing the recipient to change its resource allocation to both projects 1 and 2. However, since the recipient's current resource allocation maximizes $D$, it is just at the point where a marginal shift in resources between the two projects has zero net impact on $D$-otherwise $D$ would not currently be maximized. So, as in (2), the indirect effects cancel, leaving only the first term. Thus

$$
\frac{\partial \hat{D}}{\partial A_{1}}=\frac{\partial D_{1}}{\partial A_{1}}=\alpha_{D} A_{1}^{\alpha_{D}-1} R_{1}^{\rho_{D}}
$$

Substituting for $\hat{R}_{1}$ with (3),

$$
\frac{\partial \hat{D}}{\partial A_{1}}=\alpha_{D} A_{1}^{\alpha_{D}-1+\gamma_{D} \rho_{D}}\left(\frac{R}{A_{1}^{\gamma_{D}}+A_{2}^{\gamma_{D}}}\right)^{\rho_{D}}=\alpha_{D} A_{1}^{\gamma_{D}-1}\left(\frac{R}{A_{1}^{\gamma_{D}}+A_{2}^{\gamma_{D}}}\right)^{\rho_{D}} .
$$

(This uses the fact that $\alpha_{D}+\gamma_{D} \beta_{D}=\gamma_{D}$.) This expression is always positive.

Conclusion: if the recipient is purely developmentalist, expanding the aid pie never hurts. Adding aid expands production possibilities for the recipient, which can only cause development to increase. This is true even if the aid increase brings thousands of tiny new projects.

Example 2. The recipient is purely developmentalist and the donor moves aid from one project to another.

We use the set-up from Example 1. But this time, the donor moves aid from project 2 to project 1 while keeping total aid constant. In this case,

$$
\frac{\partial \hat{D}}{\partial A_{1}}=\frac{\partial D_{1}}{\partial A_{1}}-\frac{\partial D_{2}}{\partial A_{2}}=\alpha_{D} A_{1}^{\gamma_{D}-1}\left(\frac{R}{A_{1}^{\gamma_{D}}+A_{2}^{\gamma_{D}}}\right)^{\rho_{D}}-\alpha_{D} A_{2}^{\gamma_{D}-1}\left(\frac{R}{A_{1}^{\gamma_{D}}+A_{2}^{\gamma_{D}}}\right)^{\rho_{D}}=\alpha_{D}\left(\frac{R}{A_{1}^{\gamma_{D}}+A_{2}^{\gamma_{D}}}\right)^{\rho_{D}}\left(A_{1}^{\gamma_{D}-1}-A_{2}^{\gamma_{D}-1}\right)
$$

This is positive exactly when

$$
A_{1}^{\gamma_{D}-1}>A_{2}^{\gamma_{D}-1}
$$

which is to say, when $A_{1}>A_{2}$ and $\gamma_{D}>1$ (economies of scale dominate in development) or when $A_{1}<A_{2}$ and $\gamma_{D}<1$ (diseconomies dominate).

Conclusion: When a donor moves aid from one project to another, the recipient reallocates its resources in the same direction, and if the gaining project is more economical in scale than the old one, development goes up. Otherwise, it goes down.

Example 3. The recipient cares only about throughput and the donor increases aid to one project.

Again, we slightly modify the set-up in Example 1, this time by setting 


$$
u(D, B)=B .
$$

The first-order conditions are nearly identical to those before

$$
\begin{gathered}
\rho_{B} A_{1}^{\alpha_{B}} R_{1}^{\rho_{B}-1}=\rho_{B} A_{2}^{\alpha_{B}} R_{2}^{\rho_{B}-1}=\lambda \\
R_{1}+R_{2}=R .
\end{gathered}
$$

The solution is the same too, except that an analogously defined $\gamma_{B}$ takes the place of $\gamma_{D}$. In this case, $\gamma_{B}=1$ because we are still assuming that $\alpha_{B}+\rho_{B}=1$, so the recipient's solution is just

$$
\hat{R}_{i}=\frac{R}{A} A_{i} .
$$

The recipient allocates its resource in direct proportion to the donor's aid to each project. If the donor increases aid to project 1 while fixing project 2 's aid, then

$$
\begin{aligned}
& \frac{\partial \hat{R}_{1}}{\partial A_{1}}=\frac{\partial}{\partial A_{1}}\left[R \frac{A_{1}}{A_{1}+A_{2}}\right]=\frac{R A_{2}}{\left(A_{1}+A_{2}\right)^{2}}=\frac{A_{2}}{A} \frac{R}{A} \\
& \frac{\partial \hat{R}_{2}}{\partial A_{1}}=-\frac{\partial \hat{R}_{1}}{\partial A_{1}},
\end{aligned}
$$

the second formula following from the fixed budget constraint. The quantity of interest is

$$
\begin{gathered}
\frac{\partial \hat{D}}{\partial A_{1}}=\frac{\partial D_{1}}{\partial A_{1}}+\frac{\partial D_{1}}{\partial R_{1}} \frac{\partial \hat{R}_{1}}{\partial A_{1}}+\frac{\partial D_{2}}{\partial R_{2}} \frac{\partial \hat{R}_{2}}{\partial A_{1}} \\
=\alpha_{D} A_{1}^{\alpha_{D}-1} R_{1}^{\rho_{D}}+\rho_{D} A_{1}^{\alpha_{D}} R_{1}^{\rho_{D}-1} \frac{A_{2}}{A} \frac{R}{A}-\rho_{D} A_{2}^{\alpha_{D}} R_{2}^{\rho_{D}-1} \frac{A_{2}}{A} \frac{R}{A} .
\end{gathered}
$$

Substituting with the formula for $\hat{R}_{i}$ in (4):

$$
\frac{\partial \hat{D}}{\partial A_{1}}=\alpha_{D}\left(\frac{R}{A}\right)^{\rho_{D}} A_{1}^{\alpha_{D}+\rho_{D}-1}+\rho_{D}\left(\frac{R}{A}\right)^{\rho_{D}} A_{1}^{\alpha_{D}+\rho_{D}-1} \frac{A_{2}}{A}-\rho_{D}\left(\frac{R}{A}\right)^{\rho_{D}} A_{2}^{\alpha_{D}+\rho_{D}-1} \frac{A_{2}}{A} .
$$

Rearrangement (the details are omitted) shows that this is greater than 0 if and only if:

$$
1+\frac{\alpha_{D}}{\rho_{D}}>\frac{\frac{A_{1}}{\frac{1}{2}\left(A_{1}+A_{2}\right)}}{\frac{A_{1}^{\alpha_{D}+\rho_{D}}}{\frac{1}{2}\left(A_{1}^{\alpha_{D}+\rho_{D}}+A_{2}^{\alpha_{D}+\rho_{D}}\right)}} .
$$

It can be shown that the numerator of the grand fraction on the right is less than the denominator exactly when $A_{1}>A_{2}$ and $\alpha_{D}+\rho_{D}>1$, or when the opposite is true on both 
counts - that is, when $A_{1}$, the project gaining aid, has a more economical scale than $A_{2}$. If this holds, it guarantees the inequality since the left side is always at least 1 . Then $\partial \hat{D} / \partial A_{1}>0$ and increasing aid to project 1 increases development.

But the inequality can fail in other cases - most easily when recipient-side resources are the dominant factor in the production of development $\left(\alpha_{\mathrm{D}}\right.$ is much less than $\rho_{\mathrm{D}}$, so $\alpha_{\mathrm{D}} / \rho_{\mathrm{D}}$ +1 is low) and $A_{1}$ is far less economically scaled than $A_{2}$. In this case, the first righthand term of (5), the direct effect of the aid increase on development from project 1, is dwarfed by the second and third terms, which capture the indirect effect of the recipient's resource reallocation. And these latter terms can sum to a negative value if the recipient is reallocating resources toward the project where marginal total productivity is lower.

Conclusion: If the recipient cares only about throughput, increasing aid can reduce development if recipient-side resources are an important ingredient in development and the project receiving the increase is of a relatively uneconomical scale.

If the recipient cares both about throughput and development rather than throughput alone, the same result should hold but the mathematics are more complex. Thus, to generalize, if the recipient is not purely developmentalist, increasing aid to uneconomically scaled projects can reduce development.

Example 4. The recipient cares only about throughput and the donor moves aid from one project to another.

This time, the derivative of development with respect to the (increasing) aid to project 1 is

$$
\begin{aligned}
& \left.\frac{\partial \hat{D}}{\partial A_{1}}\right|_{A_{1}+A_{2}=A}=\frac{\partial D_{1}}{\partial A_{1}}+\frac{\partial D_{2}}{\partial A_{2}} \frac{\partial A_{2}}{\partial A_{1}}+\frac{\partial D_{1}}{\partial R_{1}} \frac{\partial \hat{R}_{1}}{\partial A_{1}}+\frac{\partial D_{2}}{\partial R_{2}} \frac{\partial \hat{R}_{2}}{\partial A_{1}} \\
& =\alpha_{D} A_{1}^{\alpha_{D}-1} R_{1}^{\rho_{D}}-\alpha_{D} A_{2}^{\alpha_{D}-1} R_{2}^{\rho_{D}}+\rho_{D} A_{1}^{\alpha_{D}} R_{1}^{\rho_{D}-1} \frac{R}{A}-\rho_{D} A_{2}^{\alpha_{D}} R_{2}^{\rho_{D}-1} \frac{R}{A} \\
& =\alpha_{D}\left(\frac{R}{A}\right)^{\rho_{D}}\left(A_{1}^{\alpha_{D}+\rho_{D}-1}-A_{2}^{\alpha_{D}+\rho_{D}-1}\right)+\rho_{D}\left(\frac{R}{A}\right)^{\rho_{D}}\left(A_{1}^{\alpha_{D}+\rho_{D}-1}-A_{2}^{\alpha_{D}+\rho_{D}-1}\right)
\end{aligned}
$$

which is positive exactly when

$$
A_{1}^{\alpha_{D}+\rho_{D}-1}>A_{2}^{\alpha_{D}+\rho_{D}-1}
$$

This occurs under the same circumstances as in Example 2.

Conclusion: If the recipient cares only about throughput, when a donor moves aid from a project with lower marginal productivity to one with higher, development goes up. Otherwise, it goes down.

Note that this conclusion is underpinned by the assumption that production of throughput has constant returns to scale. If there are large enough diseconomies of scale in throughput, then it is possible for the recipient to reallocate resources in the opposite direction from the donor, so that development can go down even when the donor is shifting aid to a more economically scaled project. 


\section{The empirical distribution of aid projects}

This section examines the distribution of aid projects more closely, again using the CRS database. The purpose is to derive an empirical relationship between the total aid going to a country and the distribution of its projects by size. This will then serve to calibrate a simulation using a more sophisticated example of the model just presented.

The distribution of projects by size, both within and across countries, follows clear patterns. In general, the distribution in a given country or group of countries is unimodal, of course has support above zero, and skews to the right. The lognormal distribution is, therefore, a promising model for the distribution, as Figures 1-3 confirm. They show the distributions of project size on a logarithmic scale, for all countries together, and for China and Tanzania alone. Project sizes are in thousands of dollars. As in Table 2, tallies are for the three most recent years of data.

Given the quality of the lognormal fit, the distribution of projects by size in a given country is well characterized by the mean and standard deviation of the corresponding distribution in $\log$ space, $\mu$ and $\sigma$. Moreover, these turn out to be strongly correlated with total project commitments. As a result, one can make a good prediction of the distribution of projects by size in a country given only the total amount, $A$, of aid committed to those projects.

Figure 1

Distribution of project commitments by size, all countries, 2001-03

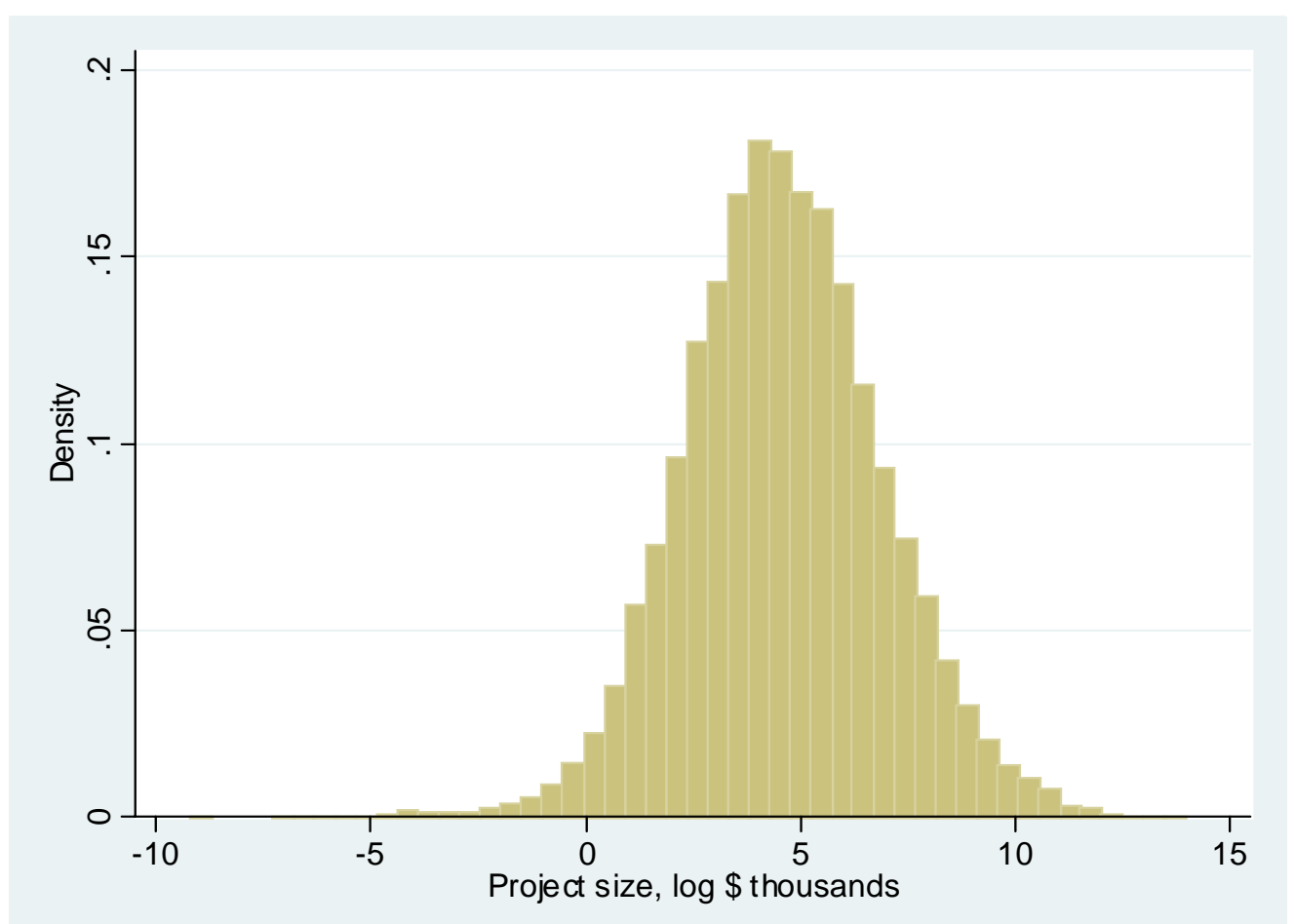

Source: Author's calculations, based on DAC (2005). 
Figure 2

Distribution of projects by size, TANZANIA, 2001-03

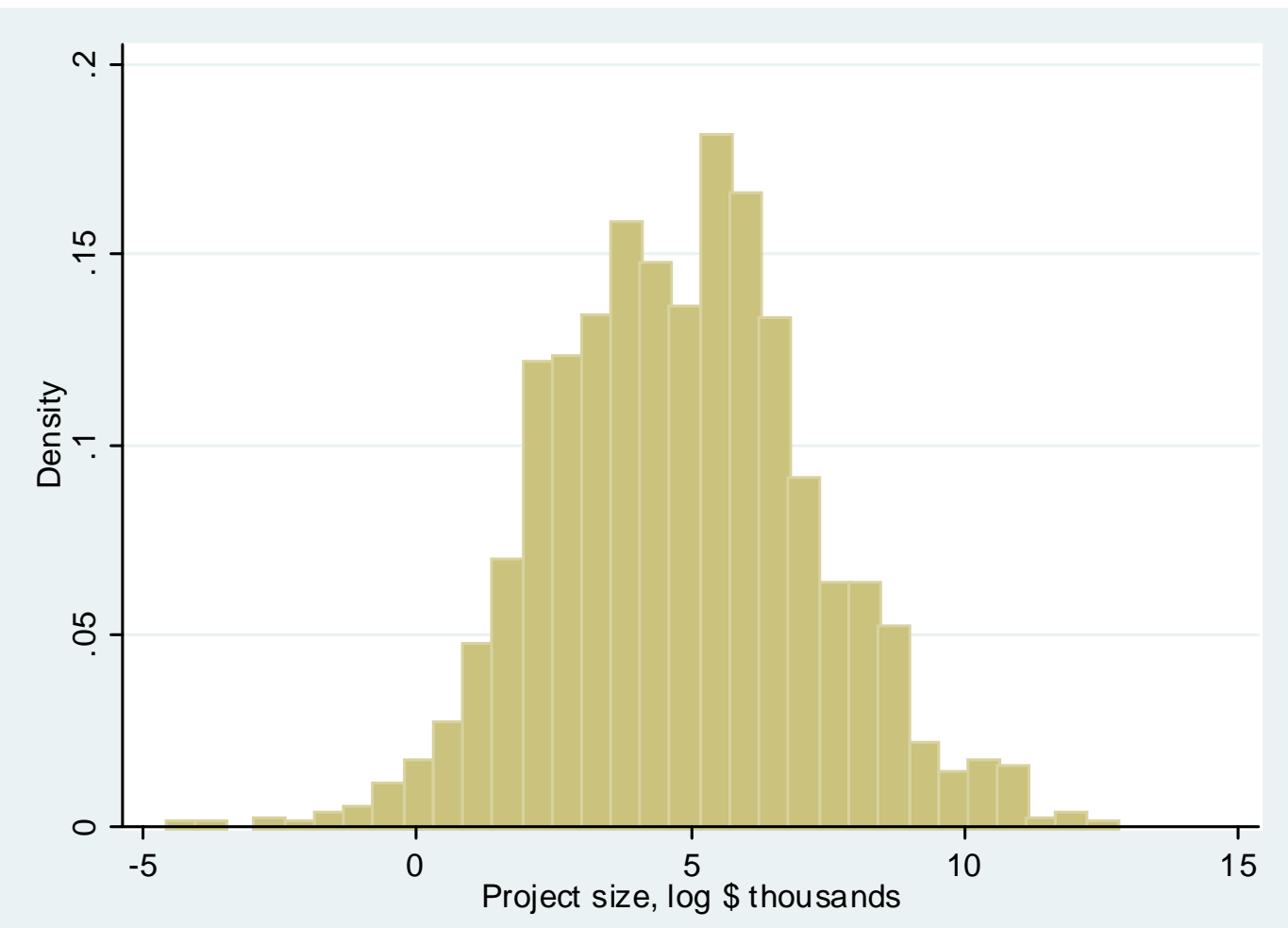

Source: Author's calculations, based on DAC (2005).

Figure 3

Distribution of projects by size, CHINA, 2001-03

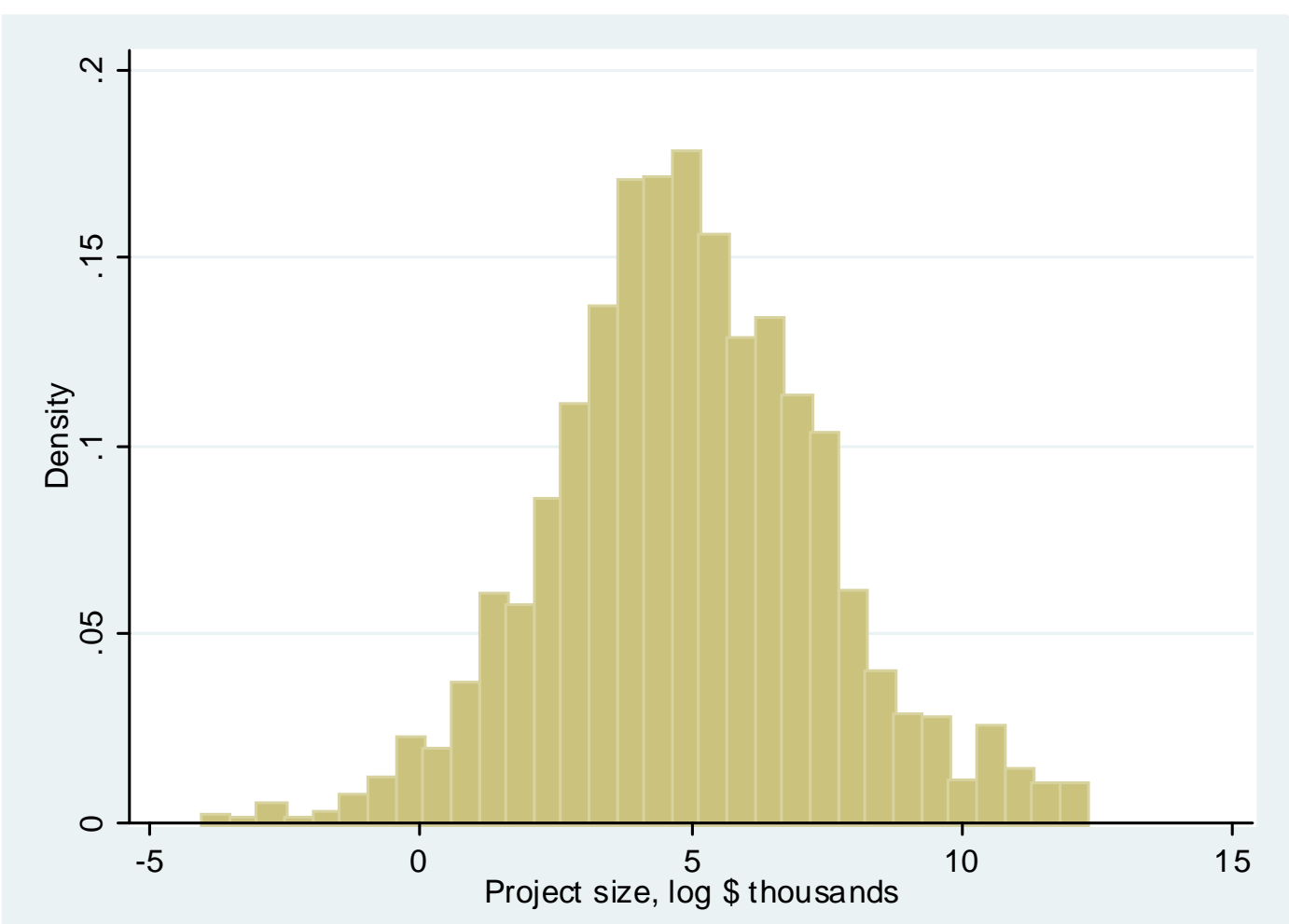

Source: Author's calculations, based on DAC (2005). 
To formalize this idea and rigorously estimate the best-fit lines, I fit the following model to the full 2001-03 dataset using maximum likelihood estimation:

$$
\begin{aligned}
& \mu=\mu_{0}+c_{\mu} \ln A \\
& \sigma=\sigma_{0}+c_{\sigma} \ln A \\
& h(x)=\frac{1}{\sqrt{2 \pi} \sigma x} e^{-\frac{1}{2 \sigma^{2}}(\ln x-\mu)^{2}}
\end{aligned}
$$

where $x$ is the size of a project, $A$ is total project funding commitments in thousands of dollars for 2001-03, and $h(x)$ is the probability density for projects of size $x$, given by the standard lognormal distribution.

I run the estimation two ways. In the first, there is a single lognormal project distribution for each recipient, as in Figures 1-3. The variables $\mu, \sigma$, and $A$ all refer to the full set of projects in a given recipient country. In the second, the sparser distributions of each donor-recipient pair are modelled, to allow for donor-level heterogeneity. Here, $\mu, \sigma$, and $A$ refer to the distribution of projects of a given donor in a given recipient country. See Table 3 . Almost all parameters are strongly different from 0 . The parameters $c_{\mu}$ and $c_{\sigma}$ are significantly higher in the second regression, meaning that for a given donor in a given recipient country, the project distribution shifts more quickly for a given aid increase than it does when aggregating across all donors.

Table 3

Maximum likelihood estimates of model parameters, 2003

\begin{tabular}{ccc}
\hline & By recipient & By donor and recipient \\
\hline$C_{\mu}$ & 0.2707 & 0.3642 \\
& $(0.0065)^{\star \star}$ & $(0.0036)^{\star \star}$ \\
$\mu_{0}$ & 0.0546 & 0.0729 \\
& $(0.0819)$ & $(0.0325)^{\star}$ \\
$C_{\sigma}$ & 0.1058 & 0.1284 \\
& $(0.0043)^{\star \star}$ & $(0.0025)^{\star \star}$ \\
$\sigma_{0}$ & 0.9580 & 0.9859 \\
& $(0.0541)^{\star \star}$ & $(0.0223)^{\star \star}$ \\
$N$ & 79,426 & 79,426 \\
\hline
\end{tabular}

Note: Standard errors in parentheses. Sample excludes Israel and recipients with population below 1 million.

* significant at $5 \%$; ** significant at $1 \%$

The regression modelling a single distribution for each recipient is the basis for the fit lines in Figures 4-6. These show the empirical average and standard deviation of log project size by recipient for the 2001-03 data, as well as the number of projects. Data points are labelled with 3-letter ISO country codes. The best-fit curve in the final graph, which plots the number of projects against total aid, is computed using the fact that the average of a lognormal distribution is $e^{\mu+\sigma^{2} / 2}$ (Aitchison and Brown 1963: 8), so that 


$$
N=\frac{A}{e^{\mu+\frac{\sigma^{2}}{2}}} .
$$

According to the upper-left cell of Table 3, a factor-of-10 increase in total project aid to a country lifts the average log project size by

$$
0.2707 \times \ln 10=0.6233
$$

which is equivalent to multiplying the geometric average of project size (which in a lognormal distribution is also the median, $e^{\mu}$ ) by a factor of

$$
e^{0.6233}=1.866
$$

Intuitively speaking, a 10-fold increase in total aid to a country is associated in the data with an 86.6 per cent rise in representative project size. Since average project size rises much more slowly than total aid, the number of projects goes up. Along the same lines, regression 2 suggests that if a single donor increases its aid for a country 10-fold, its own typical project size goes up 131 per cent. Of course these statistics tell us little about the true direction of causality. But they are useful for simulations.

\section{Figure 4}

Average log project size versus total project funding, by recipient, 2001-03

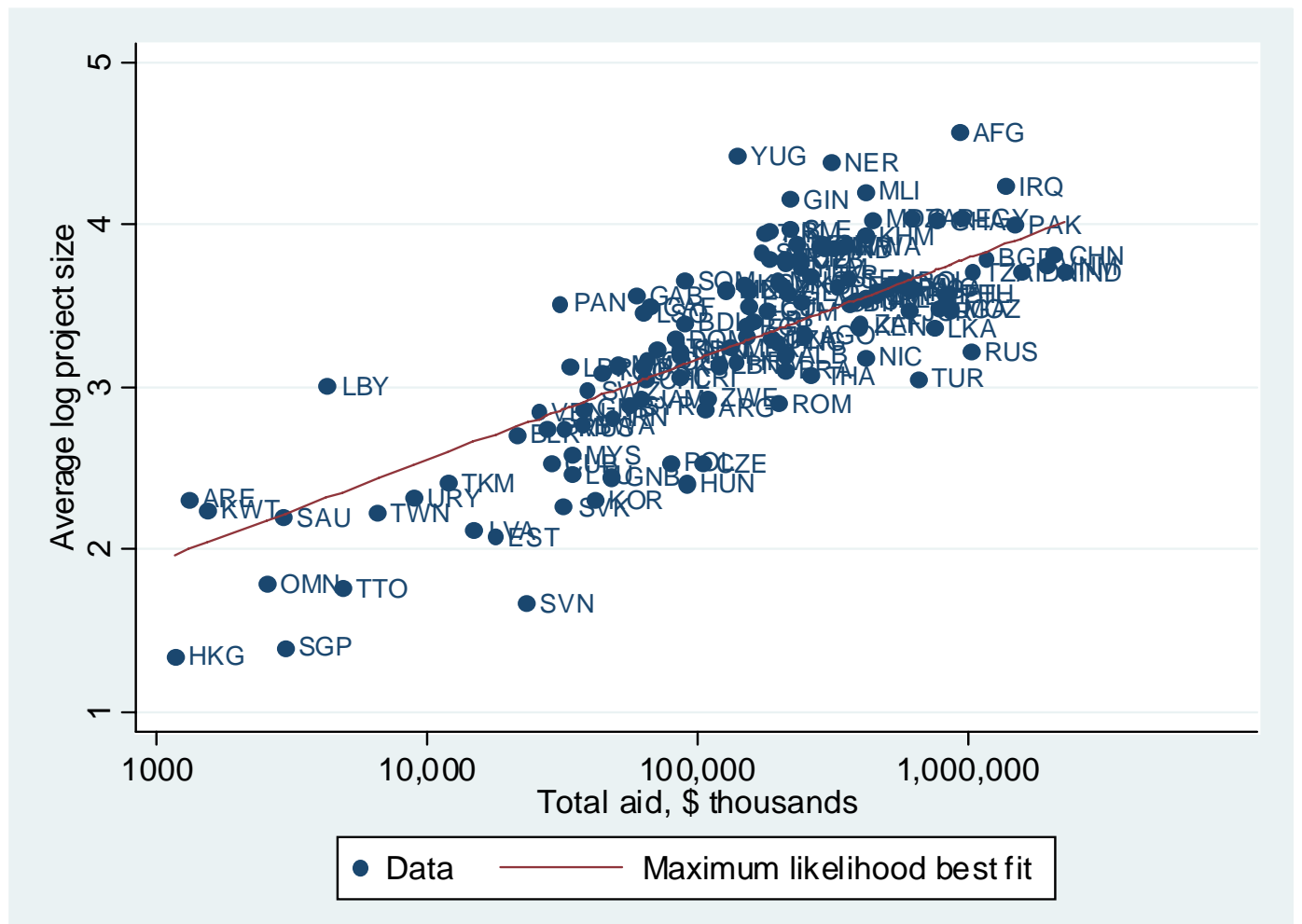

Source: Author's calculations, based on DAC (2005). 
Figure 5

Standard deviation of log project size versus total project funding, by recipient, 2001-03

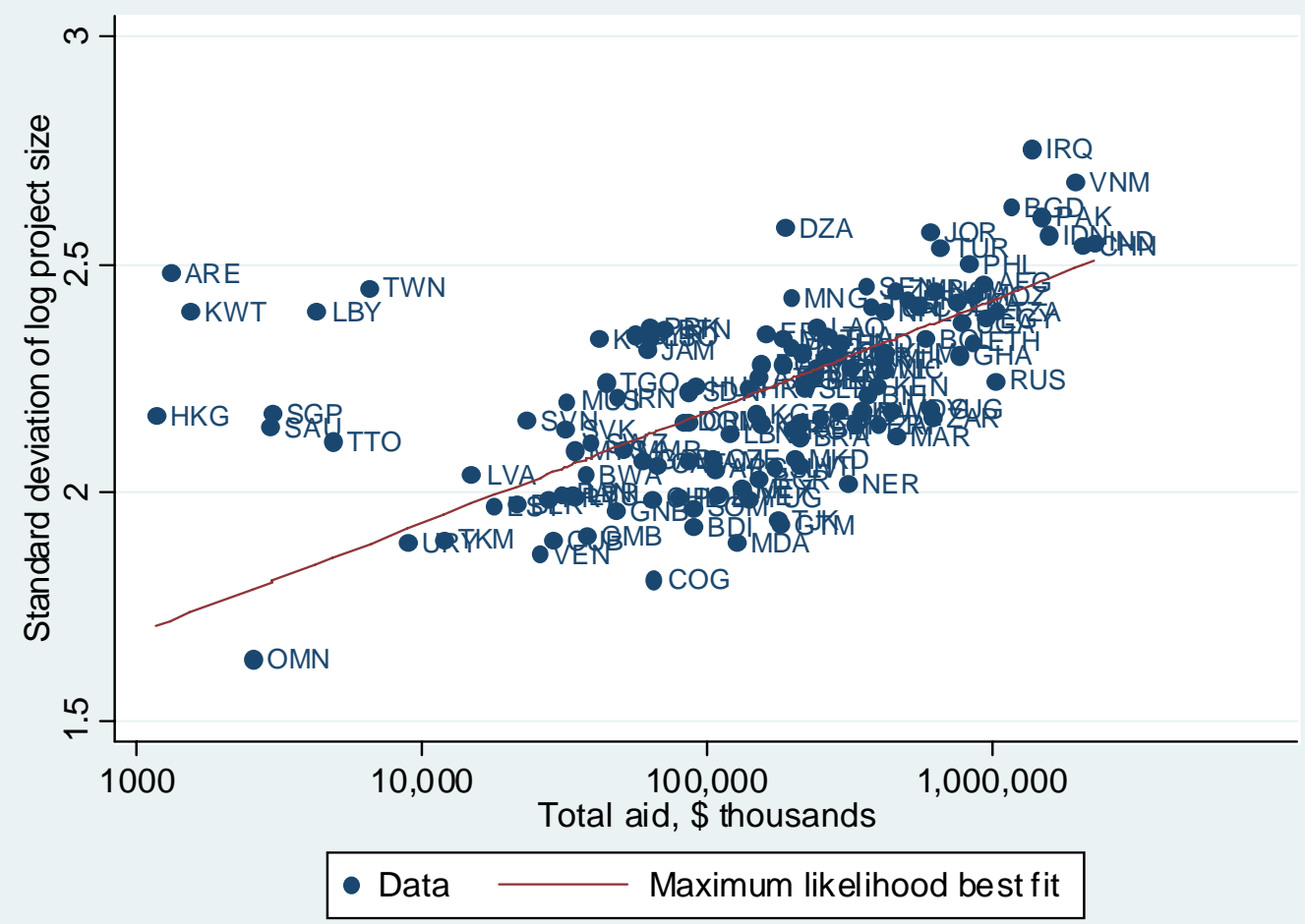

Source: Author's calculations, based on DAC (2005).

Figure 6

Number of projects versus total project funding, by recipient, 2001-03

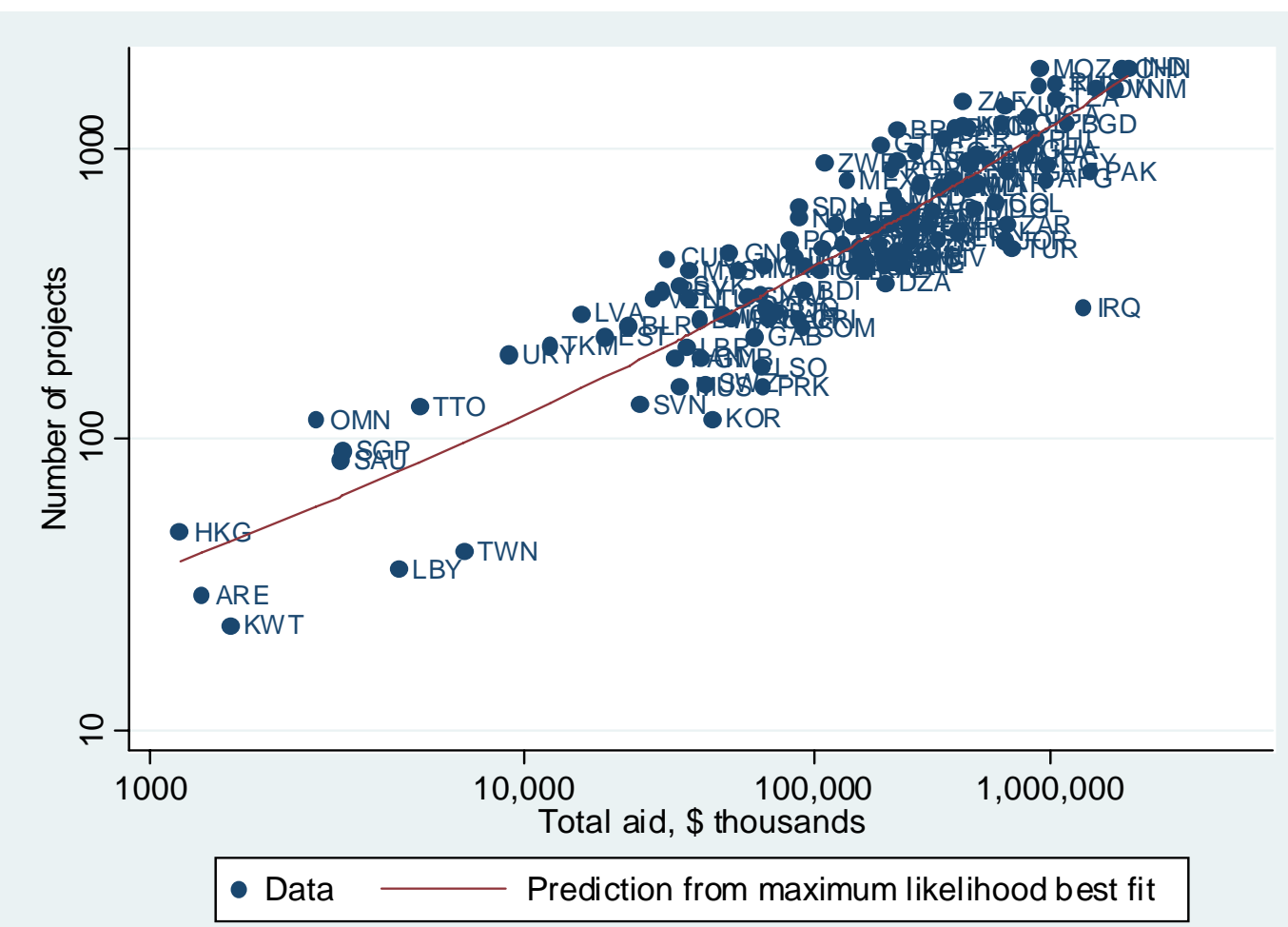

Source: Author's calculations, based on DAC (2005). 


\section{A simulation with sunk costs}

This section develops the earlier examples in two important ways. It introduces a notion of sunk cost. And it adapts the model to the continuous setting. It then reports the results of simulations partially calibrated using the empirical patterns just described.

\subsection{Sunk costs}

All of the earlier examples assume that the first penny the recipient invests in aid projects increases output of development and throughput. But it seems likely that aid projects have significant sunk costs that the recipient must cover for the project to proceed: meeting with donors in the capital, taking them on field visits, filing reports, and so on. We might expect sunk cost to rise with project size, but not as fast, according to a sunk cost function $s\left(A_{i}\right)$. This is captured in the following modified Cobb-Douglas production functions:

$$
\begin{gathered}
D_{i}=\left\{\begin{array}{cc}
0 & \text { if } R_{i} \leq s\left(A_{i}\right) \\
A_{i}^{\alpha_{D}}\left(R_{i}-s\left(A_{i}\right)\right)^{\rho_{D}} & \text { if } R_{i}>s\left(A_{i}\right)
\end{array}\right. \\
B_{i}=\left\{\begin{array}{cc}
0 & \text { if } R_{i} \leq s\left(A_{i}\right) \\
A_{i}^{\alpha_{B}}\left(R_{i}-s\left(A_{i}\right)\right)^{\rho_{B}} & \text { if } R_{i}>s\left(A_{i}\right)
\end{array}\right. \\
s \geq 0, s^{\prime} \geq 0, s^{\prime \prime} \leq 0 \text { everywhere }
\end{gathered}
$$

Unlike in the earlier examples, there will be cases in which the recipient can maximize its utility by not funding certain projects. Indeed, it may not be able to afford to put resources into all projects. In general, the recipient will invest either 0 or more than $s\left(A_{i}\right)$ in each project, since investing less than the sunk cost would produce no output and waste resources. Among the set of recipient-funded projects, $F$, the recipient will allocate its resource much as in the case where there are no sunk costs, such that marginal utility is equalized across projects. For example, if the recipient is purely developmentalist, the optimal solution is:

$$
\hat{R}_{i}=\left\{\begin{array}{cl}
\left(R-\sum_{F} s\left(A_{j}\right)\right) \frac{A_{i}^{\gamma_{D}}}{\sum_{F} A_{i}^{\gamma_{D}}}+s\left(A_{i}\right) & \text { if } i \in F \\
0 & \text { if } i \notin F
\end{array}\right.
$$

The $R-\sum_{F} s\left(A_{j}\right)$ term represents the piece of the recipient's budget that is not consumed by sunk costs, and takes the place of $R$ in (3). As in (3), the $\frac{A_{i}^{\gamma_{D}}}{\sum_{F}^{\gamma_{D}}}$ fraction determines the allocation of that piece among funded projects.

But which projects will the recipient fund? In general, if the utility and production functions are suitably differentiable, $F$ can be characterized as set of size ranges, within each of which the recipient funds all projects. One range, however, could have an upper 'bound' of infinity. In many cases, $F$ consists of a single range. 
Table 4 illustrates. It takes the case where there are five projects, of sizes 1, 2, 3, 4, and 5. It assumes that the recipient is purely developmentalist, that sunk cost rises with the square-root of aid $\left(s\left(A_{i}\right)=\sqrt{A_{i}}\right)$, and that development is $D=A_{i}^{0.5}\left(R_{i}-s\left(A_{i}\right)\right)^{0.5}$. The table shows how the recipient's resource allocation evolves as its budget envelope expands. When the resource budget, $R$, is just 0.5 , the recipient cannot cover the sunk cost of even the smallest project, project 1 . As $R$ increases, the recipient can afford project 1 , and funds it. With further increases, it shifts to larger projects. As $R$ rises above 6 , it becomes possible and optimal for the recipient to fund two projects, then three, and eventually all the projects. In this case, $F$ is always contiguous.

Table 4

Optimal allocation of recipient resource of among five projects of size 1, 2, 3, 4, and 5 as resource budget $R$ rises

\begin{tabular}{rlllll}
\hline \multicolumn{5}{c}{ Optimal allocation } & \\
\hline$R$ & $R_{1}$ & $R_{2}$ & $R_{3}$ & $R_{4}$ & $R_{5}$ \\
\hline 0.5 & 0 & 0 & 0 & 0 & 0 \\
1.0 & 0 & 0 & 0 & 0 & 0 \\
1.5 & 1.50 & 0 & 0 & 0 & 0 \\
2.0 & 0 & 2.00 & 0 & 0 & 0 \\
2.5 & 0 & 0 & 2.50 & 0 & 0 \\
3.0 & 0 & 0 & 0 & 3.00 & 0 \\
4.0 & 0 & 0 & 0 & 0 & 4.00 \\
5.0 & 0 & 0 & 0 & 0 & 5.00 \\
6.0 & 0 & 0 & 0 & 0 & 6.00 \\
7.0 & 0 & 0 & 0 & 3.23 & 3.77 \\
8.0 & 0 & 0 & 0 & 3.67 & 4.33 \\
9.0 & 0 & 0 & 0 & 4.12 & 4.88 \\
10.0 & 0 & 0 & 0 & 4.56 & 5.44 \\
11.0 & 0 & 0 & 0 & 5.01 & 5.99 \\
12.0 & 0 & 0 & 3.24 & 4.01 & 4.75 \\
13.0 & 0 & 0 & 3.49 & 4.34 & 5.17 \\
14.0 & 0 & 0 & 3.74 & 4.68 & 5.58 \\
15.0 & 0 & 0 & 3.99 & 5.01 & 6.00 \\
16.0 & 0 & 2.65 & 3.58 & 4.46 & 5.31 \\
17.0 & 0 & 2.79 & 3.79 & 4.75 & 5.67 \\
18.0 & 0 & 2.93 & 4.01 & 5.03 & 6.03 \\
19.0 & 0 & 3.07 & 4.22 & 5.32 & 6.39 \\
20.0 & 0 & 3.22 & 4.44 & 5.61 & 6.74 \\
30.0 & 1.97 & 3.36 & 4.65 & 5.88 & 7.09 \\
\hline & & & & & \\
\hline
\end{tabular}

\section{Moving to the continuous setting}

We can replace the finite set of projects, $\left\{A_{i}\right\}$, in the original framework with a continuous function $h()$ that gives the density of projects of a given size. Assuming that the recipient puts the same amount of resource into each project of any given size, which it should by symmetry, its resource allocation rule can be expressed as function 
of project size: $r(x)$. The Cobb-Douglas production functions from the previous section become:

$$
\begin{aligned}
& D=\int_{F} x^{\alpha_{D}}(r(x)-s(x))^{\rho_{D}} h(x) d x \\
& B=\int_{F} x^{\alpha_{B}}(r(x)-s(x))^{\rho_{B}} h(x) d x
\end{aligned}
$$

where $F$ is the set of funded projects, $\{x \mid r(x) \geq s(x)\}$. The mathematics of the recipient's problem is identical whether it is a pure development or a pure throughput optimizerthe two cases that are most tractable. So consider the case when the recipient is purely developmentalist. Its problem is

$$
\begin{aligned}
& \max _{r(x)} D \\
& \text { such that } \int_{\mathrm{F}} r(x) h(x) d x=R .
\end{aligned}
$$

By analogy with the discrete case, the natural candidate solution is (compare to (7)):

$$
\hat{r}(x)=\left\{\begin{array}{cl}
\left(R-\int_{F} s(y) h(y) d y\right) \frac{x^{\gamma_{D}}}{\int_{F} y^{\gamma_{D}} h(y) d y}+s(x) & \text { if } i \in F \\
0 & \text { if } i \notin F
\end{array} .\right.
$$

We must apply the calculus of variations to confirm that (11) is the optimum for a given $F$. This is more easily done if the problem is recast so that the budget constrain becomes a boundary condition. So define:

$$
\begin{gathered}
R(x) \equiv \int_{0}^{x} r(y) h(y) d y \\
\delta(x) \equiv x^{\alpha_{D}}(r(x)-s(x))^{\rho_{D}} h(x)=x^{\alpha_{D}}\left(\frac{R^{\prime}(x)}{h(x)}-s(x)\right)^{\rho_{D}} h(x) .
\end{gathered}
$$

Thus according to (8),

$$
D=\int_{F} \delta(x) d x
$$

The recipient's problem is then

$$
\begin{aligned}
& \max _{R(x)} \int_{F} \delta(x) d x \\
& \text { such that } R(0)=0 \text { and } R(\infty)=R .
\end{aligned}
$$

This is a calculus of variations problem in which the integrand depends on the derivative of the argument, but not the argument itself: $\delta(x)$ depends on $R^{\prime}(x)$ but not 
$R(x)$. The version of the Euler equation that $R(x)$ must satisfy in this case is

$$
\frac{d}{d x}\left(\frac{d \delta}{d R^{\prime}}\right)=0
$$

(Chiang 1992: 37). Differentiating (12),

$$
\frac{d \delta}{d R^{\prime}}=\rho_{D} x^{\alpha_{D}}\left(\frac{R^{\prime}(x)}{h(x)}-s(x)\right)^{\rho_{D}-1}=\rho_{D} x^{\alpha_{D}}(r(x)-s(x))^{\rho_{D}-1} .
$$

Plugging in the trial solution for $r(x)$ in (11),

$$
\begin{aligned}
\frac{d \delta}{d R^{\prime}} & =\rho_{D} x^{\alpha_{D}}\left(\left(R-\int_{F} s(y) h(y) d y\right) \frac{x^{\gamma_{D}}}{\int_{F} y^{\gamma_{D}} h(y) d y}+s(x)-s(x)\right)^{\rho_{D}-1} \\
& =\rho_{D}\left(\frac{R-\int_{F} s(y) h(y) d y}{\int_{F} y^{\gamma_{D}} h(y) d y}\right)^{\rho_{D}-1} x^{\alpha_{D}+\gamma_{D}\left(\rho_{D}-1\right)} .
\end{aligned}
$$

Since $\gamma_{D}=\alpha_{D} /\left(1-\rho_{D}\right), x^{\alpha_{D}+\gamma_{D}\left(\rho_{D}-1\right)}=1$. The above expression therefore does not vary with $x$, so it satisfies the Euler equation, as needed.

Equation (11) describes the recipient's solution given the set of funded projects, $F$, but does not include a recipe for $F$. To study $F$, we first substitute the formula for the recipient's optimal allocation within $F$ (equation 11) back into the equation for $D$ in (8):

$$
\begin{aligned}
D & =\left(\frac{R-\int_{F} s(x) h(x) d x}{\int_{F} x^{\gamma_{D}} h(x) d x}\right)_{F}^{\rho_{D}} \int_{F} x^{\alpha_{D}}\left(x^{\gamma_{D}}\right)^{\rho_{D}} h(x) d x=\left(\frac{R-\int_{F} s(x) h(x) d x}{\int_{F} x^{\gamma_{D}} h(x) d x}\right)_{F}^{\rho_{B}} \int_{F} x^{\gamma_{D}} h(x) d x \\
& =\left(\int_{F} x^{\gamma_{D}} h(x) d x\right)^{1-\rho_{D}}\left(R-\int_{F} s(x) h(x) d x\right)^{\rho_{D}}
\end{aligned}
$$

(taking advantage in the second step of the fact that $\alpha_{D}+\gamma_{D} \beta_{D}=\gamma_{D}$ ).

It is impossible to write down a general, explicit solution for the $F$ that maximizes this geometric average of integrals. However $F$ can be tightly characterized, assuming sunk cost has constant elasticity with respect to project size. 
Proposition. If we can write $s(x)=s_{0} x^{c_{s}}$, then the set $F$ that maximizes (14) is almost always contiguous and takes the form $(0, \mathrm{MAX}]$ or $[\mathrm{MIN}, \infty)$ where MIN, MAX $>0$.

In other words, except in certain degenerate examples, the recipient's optimal strategy is to fund all projects below a certain size or all projects above a certain size-or, as a special case of the latter, all projects of any size $(\mathrm{MIN}=0)$.

Proof. A priori, $F$ could consist of multiple disjoint segments within the set of nonnegative numbers. Let $S=\left[x_{1}, x_{2}\right]$ be such a segment. Then (14) can be expanded to

$$
\begin{aligned}
D & =\left(\int_{F} x^{\gamma_{D}} h(x) d x\right)^{1-\rho_{D}}\left(R-\int_{F} x^{c_{s}} h(x) d x\right)^{\rho_{D}} \\
& =\left(\int_{x_{1}}^{x_{2}} x^{\gamma_{D}} h(x) d x+\int_{F-S} x^{\gamma_{D}} h(x) d x\right)^{1-\rho_{D}}\left(R-s_{0}\left(\int_{x_{1}}^{x_{2}} x^{c_{s}} h(x) d x+\int_{F-S} x^{c_{s}} h(x) d x\right)\right)^{\rho_{D}}
\end{aligned}
$$

Analysis of how to maximize (15) is easier if we work with its logarithm. Since $x_{1}$ and $x_{2}$ are parameters within the recipient's control, at a maximum, $x_{1}$ and $x_{2}$ are each either roots of a derivative of $\ln u$ or boundary solutions:

$$
\begin{aligned}
& \partial(\ln D) / \partial x_{1}=0 \text { or } x_{1}=0 \\
& \partial(\ln D) / \partial x_{2}=0 \text { or } x_{2}=\infty
\end{aligned}
$$

If $x_{1}$ is an interior solution, then differentiating the log of (15) leads to

$$
0=\frac{\partial(\ln D)}{\partial x_{1}}=\left(1-\rho_{D}\right) \frac{-x_{1}^{\gamma_{D}} h\left(x_{1}\right)}{\int_{x_{1}}^{x_{2}} x^{\gamma_{D}} h(x) d x+\int_{F-S} x^{\gamma_{D}} h(x) d x}-\rho_{D} \frac{-s_{0} x_{1}^{c_{s}} h\left(x_{1}\right)}{R-s_{0}\left(\int_{x_{1}}^{x_{2}} x^{c_{s}} h(x) d x+\int_{F-S} x^{c_{s}} h(x) d x\right)} .
$$

Rearranging,

$$
x_{1}^{\gamma-c_{s}}=\frac{\rho_{D}}{1-\rho_{D}} \frac{\int_{x_{1}}^{x_{2}} x^{\gamma_{D}} h(x) d x+\int_{F-S} x^{\gamma_{D}} h(x) d x}{R / s_{0}-\left(\int_{x_{1}}^{x_{2}} x^{c_{s}} h(x) d x+\int_{F-S} x^{c_{s}} h(x) d x\right)} .
$$

Similarly, it works out that if $x_{2}$ is an interior solution,

$$
x_{2}^{\gamma-c_{s}}=\frac{\rho_{D}}{1-\rho_{D}} \frac{\int_{x_{1}}^{x_{2}} x^{\gamma_{D}} h(x) d x+\int_{F-S} x^{\gamma_{D}} h(x) d x}{R / s_{0}-\left(\int_{x_{1}}^{x_{2}} x^{c_{s}} h(x) d x+\int_{F-S} x^{c_{s}} h(x) d x\right)}
$$

which is almost identical to (16). So if $x_{1}$ and $x_{2}$ are both interior, $x_{1}^{\gamma-c_{s}}=x_{2}^{\gamma-c_{s}}$. This equation only admits solutions in special cases, which are unrepresentative and degenerate, in the sense that an infinitesimal perturbation of the parameters will cause them to disappear. If $\gamma$ exactly equals $c_{s}$, then the equation has infinitely many 
solutions. But if they differ even infinitesimally it has only one: $x_{1}=x_{2}$. But if $x_{1}=x_{2}$ is itself a degenerate solution in the continuous setting since the integrals bounded by $x_{1}$ and $x_{2}$ in (15) are 0 . Thus in general $x_{1}$ and $x_{2}$ are not both interior. $x_{1}$ takes a boundary value $(0)$ or $x_{2}$ effectively does $(\infty)$, or both.

The above argument shows that $S$ takes the form asserted in the proposition. But $S$ is only one piece of $F$. In general, since $F$ is the disjoint union of segments in such forms, it could itself take one of those forms. Or it might take the form $\left(0, x_{1}\right] \cup\left[x_{2}, \infty\right)$, where $0<x_{1}<x_{2}$. But an argument almost identical to the one above shows that it cannot. In particular, such an $F$ could only be a maximum if $x_{1}=0$ or $x_{2}=\infty$ or $x_{1}=x_{2}$, none of which allows $F$ to be disconnected.

So as a matter of algorithm, the maximizing recipient investigates two strategiesfunding projects below or above a certain size. In each strategy, it seeks the size threshold, if any, that achieves a local maximum in utility. It then determines which local optimum is the global one. Again, all of the forgoing applies mutatis mutandis if the recipient is a pure throughput rather than development optimizer.

One final result needed to run the simulations below is the formula for development when the recipient maximizes throughput. Substituting (11) into (8),

$$
D=\left(\frac{R-\int_{F} s(x) h(x) d x}{\int_{F} x^{\gamma_{B}} h(x) d x}\right)^{\rho_{D}} \int_{F} x^{\alpha_{D}+\gamma_{B} \rho_{D}} h(x) d x .
$$

\section{The simulations}

The idea of the simulations is to watch how the recipient's resource allocation shifts as the distribution of aid projects on offer evolves, and to see how this affects development. Projects are simulated as lognormally distributed and completely determined by a single parameter, total aid, according to (6). Using the empirical parameters in column 1 of Table 3, it is assumed that

$$
\begin{aligned}
& \mu=\mu_{0}+c_{\mu} \ln A=0.0546+0.2707 \ln A \\
& \sigma=\sigma_{0}+c_{\sigma} \ln A=0.9580+0.1058 \ln A .
\end{aligned}
$$

where $A$ is in thousands of dollars. Recall that as $A$ increases, the number of projects also increases, producing 'proliferation'.

The simulations further assume 


$$
\begin{gathered}
\delta=a^{0.6}(r-s(a))^{0.6} \text { or } a^{0.4}(r-s(a))^{0.4} \\
b=a^{0.8}(r-s(a))^{0.2} \\
D=\int \delta \\
B=\int b \\
u(D, B)=B \\
s(a)=0.5 a^{0.8} \\
R=200,000 .
\end{gathered}
$$

In words, development can has increasing returns to scale in one variant and decreasing returns in another. The recipient cares only about throughput. The variables $r$ and $s$ are taken in thousands of purchasing-power-parity (PPP) dollars. Thus the production of development has increasing returns to scale once past sunk costs $(0.6+0.6>1)$, while throughput has constant returns to scale and is a product mainly of how much aid goes into a project. $R$ and $r$, like $A$ and $r$, are taken to be in thousands of dollars. However they, along with $s$, are interpreted as being in purchasing power parity dollars. Sunk costs are US\$500 PPP for a US\$1,000 (exchange rate) project and rise with an elasticity of 0.9 with respect to size - so that, for example, those for a US $\$ 1,000,000$ project (exchange rate) are about US\$250,000 PPP. The resource budget is US\$200 million, 1 per cent of the PPP GDP of Tanzania, a country often pointed to as suffering from project proliferation. These parameter choices are meant to be reasonable and minimally arbitrary.

The simulations are not Monte Carlo. Representative project distributions are not generated. Rather, the problem is tackled analytically with the mathematics above, with the core challenge being to find the minimum or maximum project size that the recipient will fund in order to maximize the throughput analog of (14). The simulation is performed using an object-oriented Visual Basic for Applications programme and accessed via user-defined functions in Microsoft Excel. The search algorithm for determining the minimum or maximum project sizes funded by the recipient is the 'dbrent' routine in Press et al. (1988).

Figure 7 shows how key variables evolve as aid rises in the variant with increasing returns to scale in development. Note first that the optimized value of $B$, called $\hat{B}$, rises monotonically with $A$-as it should since this is what the recipient is maximizing, and increasing $A$ only adds new production possibilities; similarly for the maximum achievable value of $D$, called $\hat{D}$, which is computed according to (14). But the actual value of $D$, given by (17), lags behind the ideal value, since the recipient is not maximizing it. For low aid levels, the ratio $D / \hat{D}$ is close to unity (graphed against the right axis), but around US\$100 million, the ratio plunges dramatically, bottoming out after US\$1 billion in total aid. Meanwhile, growth of development slows with respect to growth in aid, but never quite goes negative. For comparison, in this dataset, Tanzania receives US\$1.3 billion in project aid in 2003.

What is behind the divergence between potential and actual development, between $D$ and $\hat{D}$ ? At low aid levels, the recipient's budget is ample enough that it is optimal to fund 
essentially all projects - regardless of whether the recipient is maximizing development or throughput. 4 The recipient does not allocate its resource among these projects quite the way it would if it were maximizing development (it favours smaller projects, relatively), though the difference does not have a large impact. But as aid rises and projects proliferate, and because the recipient cares only about throughput, it is more reluctant to de-fund small projects with high transaction cost than it would be if it were intent on exploiting the scale economies of larger projects to maximize development. The gap becomes noticeable when total aid reaches some US\$130 million. At this point, the optimal minimum project size for the recipient to fund is US $\$ 300,000$ in aid-optimal, that is, if it is maximizing development. But from the recipient's throughput point of view, the optimal threshold is still only half a penny. (See Figure 8.) However, as total sunk costs continue rising (the bottom line in Figure 7), they eventually force even the throughput-minded recipient to defund small projects. The throughput-optimized size minimum then enters a catch-up period with respect to the development-optimized size minimum. But it never fully catches up, and so the ratio between actual development and potential development is permanently lowered.

The second simulation differs from the first in that the exponents in the Cobb-Douglas function for development are 0.4 instead of 0.6. Now there are diminishing returns to scale. Figure 9 shows that because the development production function again differs from the throughput production that the recipient maximizes, aid is still not deployed optimally. However, the divergence this time is even sharper once it begins, and shows no signs of stopping even as aid passes US\$10 billion, in that $D / \hat{D}$ continues declining.

Figure 7

Simulation with economies of scale in development

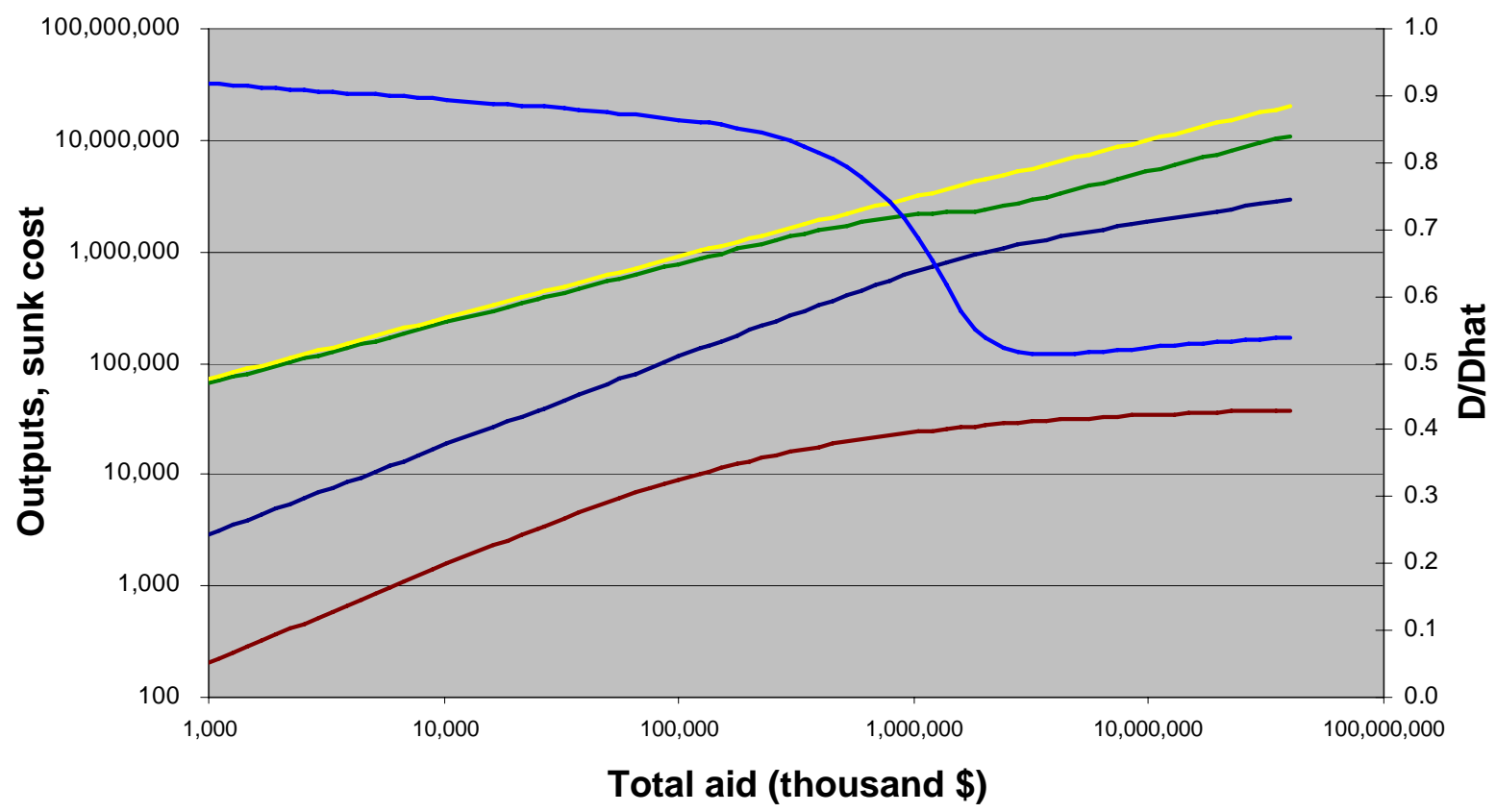

Bhat — Actual D - Max possible D (Dhat) — Sunk cost —D/Dhat

Source: Author's calculations.

4 'Essentially all' means that the minimum funded project size is a penny or less. 
Figure 8

Simulation with economies of scale in development: minimum size of projects the recipient funds

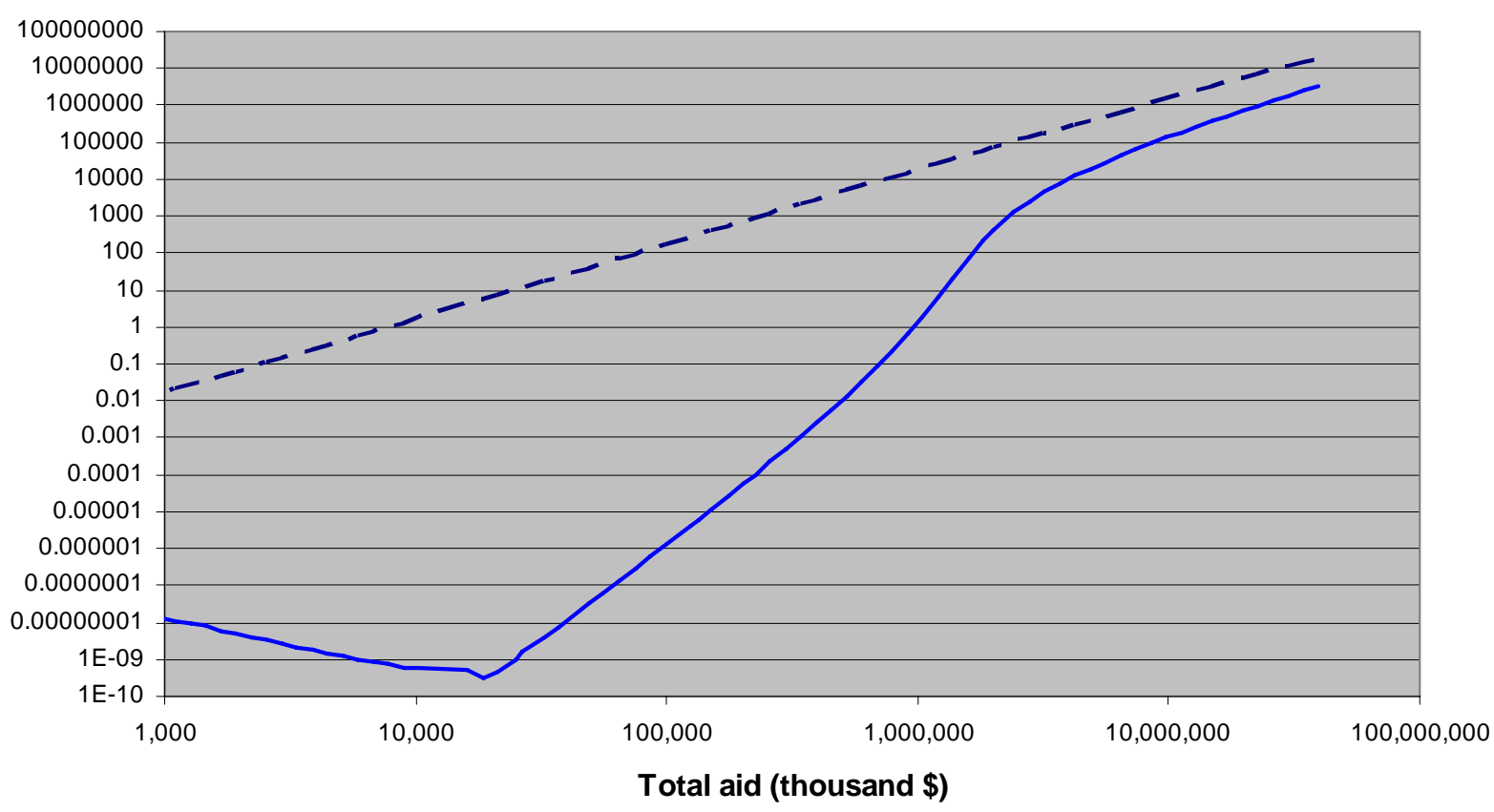

_ If optimizing throughput - - If optimizing development

Source: Author's calculations.

Figure 9

Simulation with diseconomies of scale in development

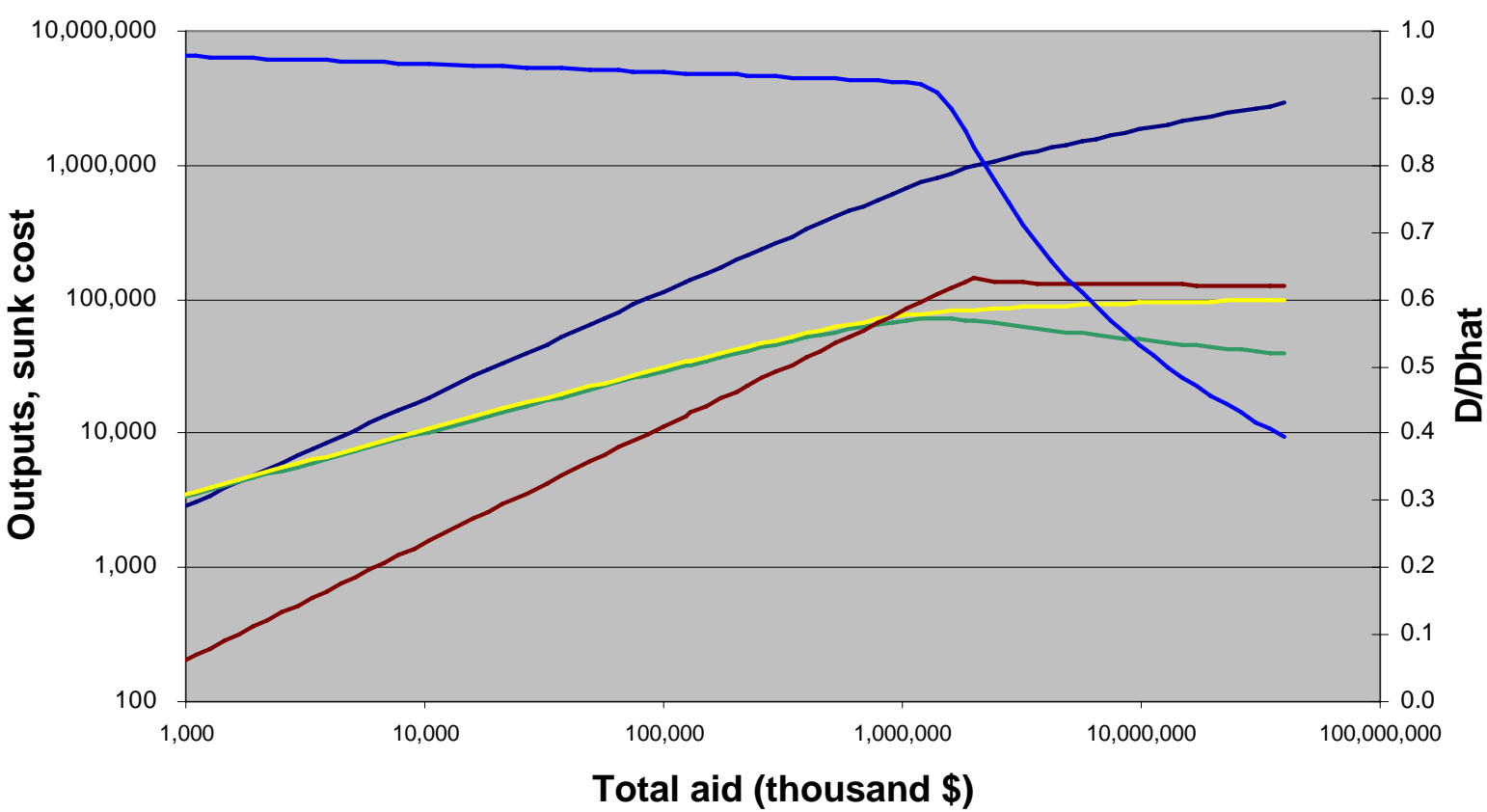

Bhat $\_$Actual D _ Max possible D (Dhat) — Sunk cost —D/Dhat

Source: Author's calculations. 
Figure 10

Simulation with diseconomies of scale in development: threshold size of projects the recipient funds
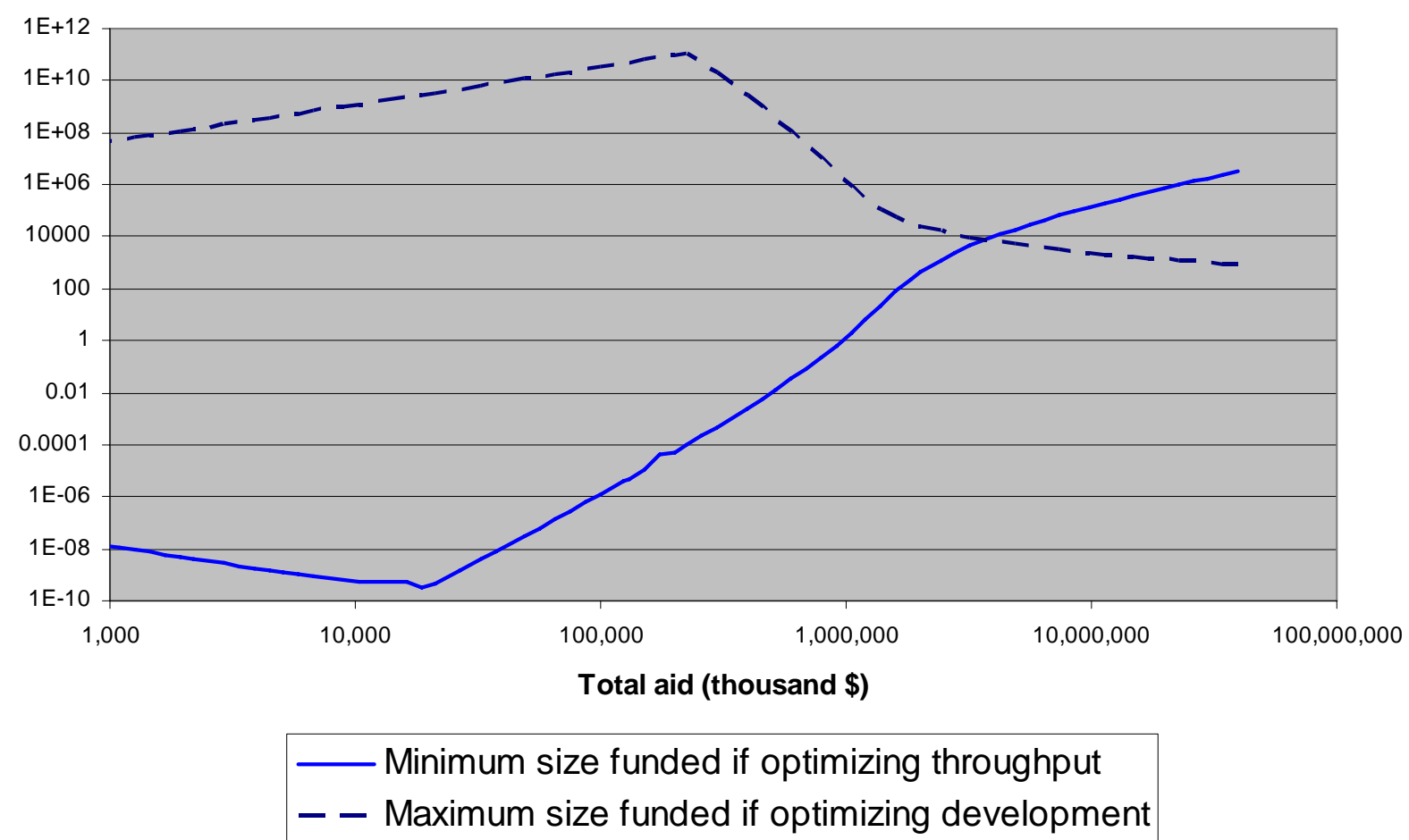

Source: Author's calculations.

Figure 11

Sensitivity analysis: varying $c_{\mu}$, the coefficient on total aid for average log project size

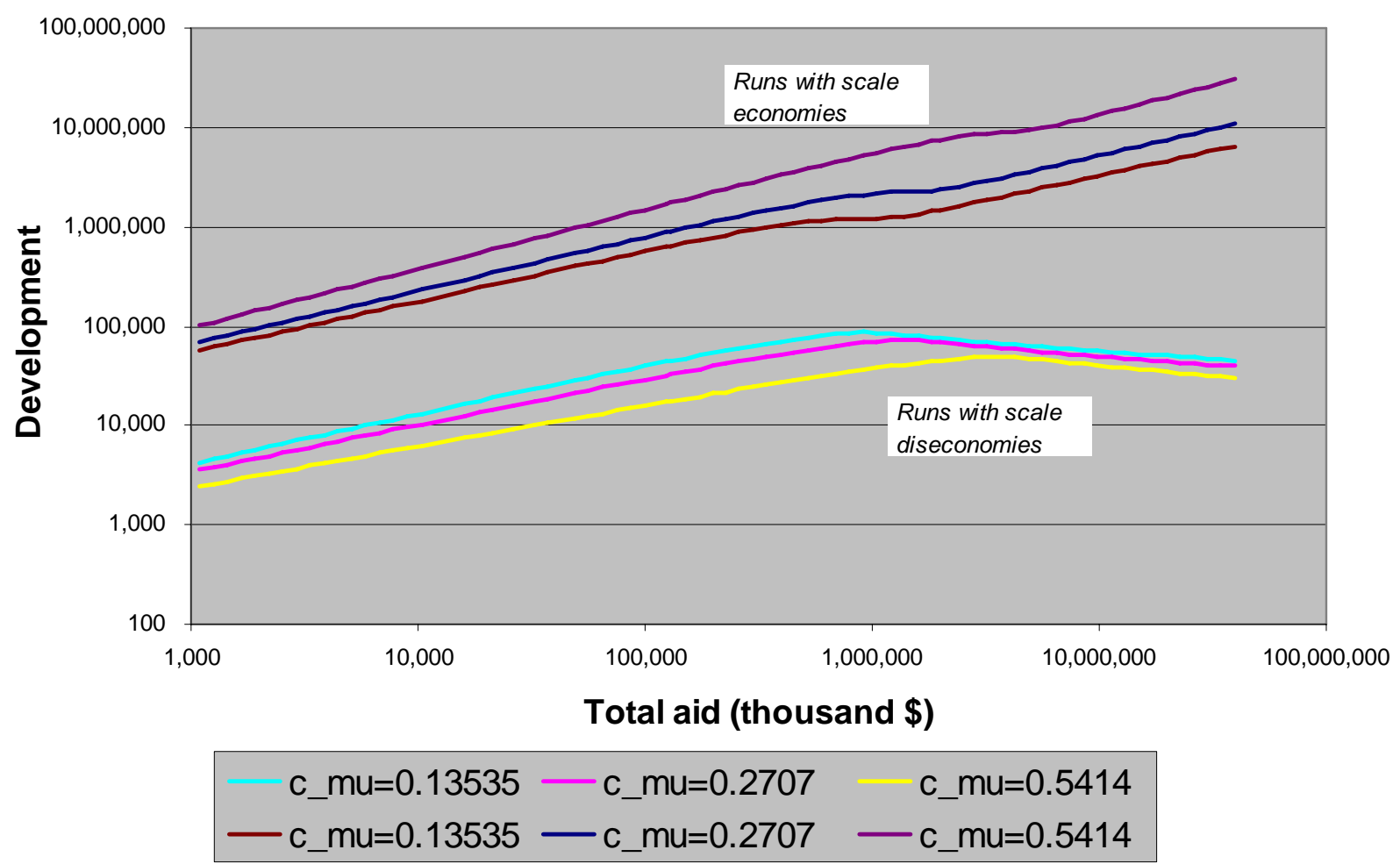

Source: Author's calculations. 
Figure 12

Sensitivity analysis: varying $c_{\sigma}$, the coefficient on total aid for standard deviation of log project size

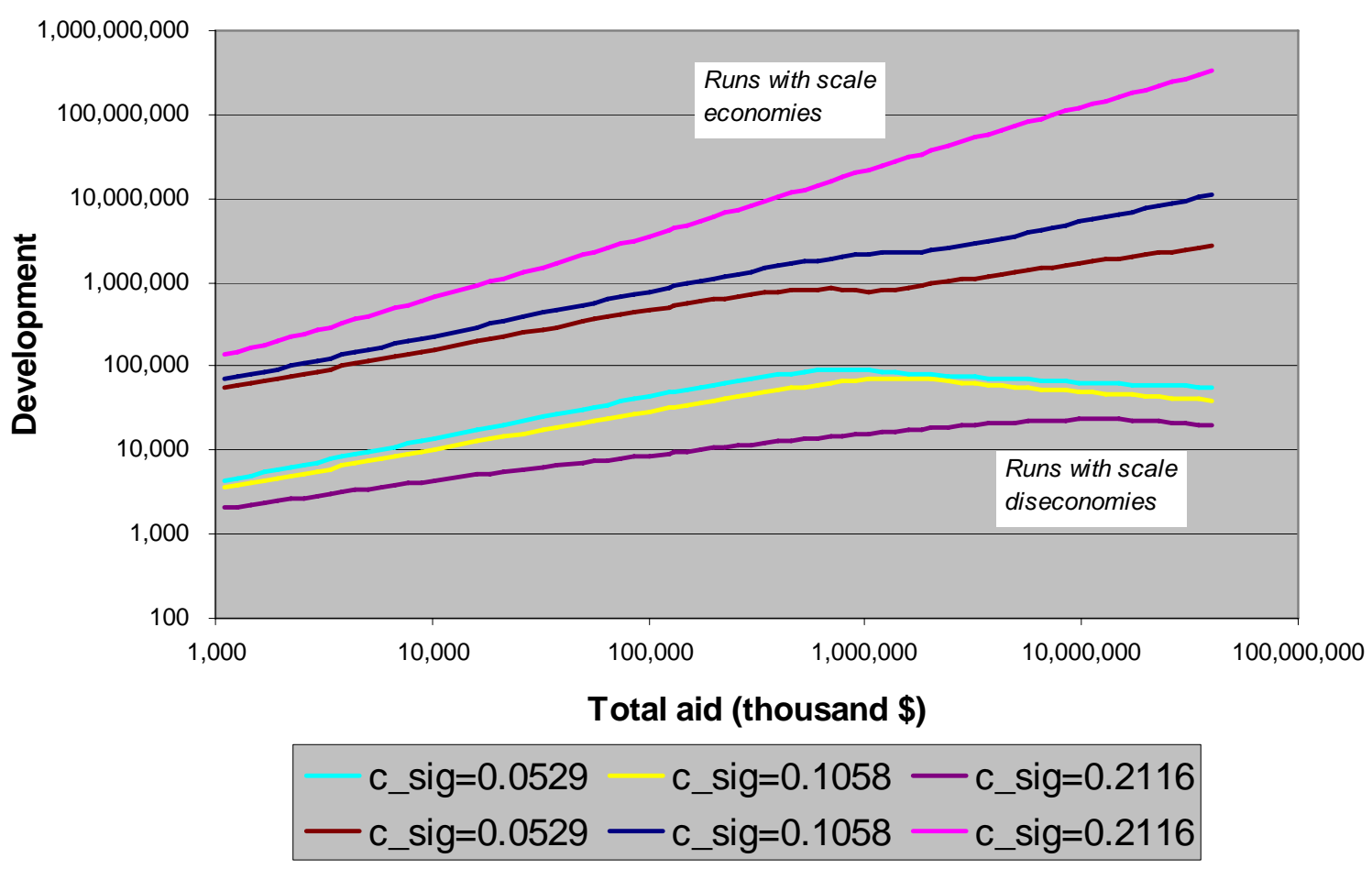

Source: Author's calculations.

Sensitivity analysis: varying coefficient on total aid for standard deviation of log project size

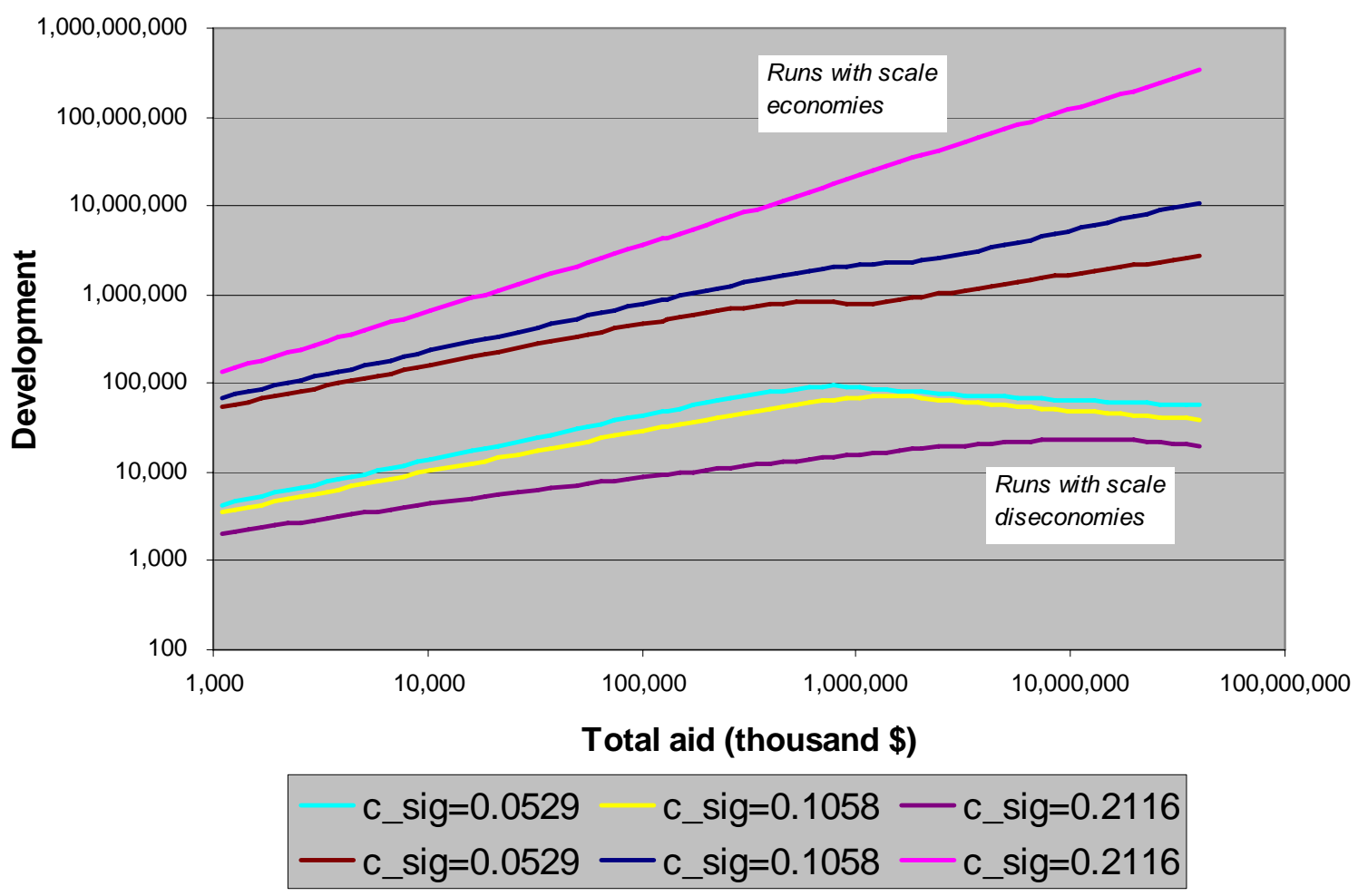


In fact, development declines in absolute terms. Why? This time the recipient departs from the development-optimal path not just in parameter choice, but in strategy. Because of the scale diseconomies, development is maximized when the recipient chooses to de-fund the largest projects. But the throughput-maximizing recipient instead de-funds the smallest projects, as shown in Figure 10.

As a sensitivity test, Figure 11 and Figure 12 show how the path for $D$ changes when two crucial parameters are varied. Figure 11 shows the effect of halving or doubling $c_{\mu}$, the coefficient on total aid in the equation for $\mu$, relative to its empirically derived value of 0.2707 . Higher values of $c_{\mu}$ lead to larger, fewer projects. Figure 11 does the same for $c_{\sigma}$, whose empirical value is 0.1058 . Not surprisingly, increasing $c_{\mu}$ raises the aid level at which the development curve starts to bend. And when there are scale economies in development, it also substantially raises development for a given level of aid, especially once above that bend. However, when there are diseconomies of scale, varying $c_{\mu}$ has much less impact. It raises the aid level at which the marginal impact goes negative, but, strikingly, lowers the peak value for development. This is because the benefits from larger projects of lower sunk costs and fewer de-funded projects are offset by scale diseconomies. The overall picture is one of a hard ceiling on development impact when project economics favour small projects, which makes sense if the recipient government can only handle so many projects. The picture is similar for $c_{\sigma}$, for in a lognormal distribution $\sigma$ also influences average project size according to the formula $e^{\mu+\sigma^{2} / 2}$.

\section{Conclusion}

The above simulations assume for simplicity that the recipient cares only about throughput. If we assume, more realistically, that the recipient cares about both throughput and development, then the same pattern should appear, but less strongly. What is important is that three features of the model - the recipient not being purely developmentalist, differences in the throughput and development production functions, and sunk costs - interact to generate a notion of absorptive capacity for aid. Above a certain threshold level, the marginal productivity of aid declines precipitouslyassuming, that is, that aid increase goes hand in hand with a pattern of project proliferation that is typical in the current cross-section of countries. The deep source of this threshold is the discontinuous nature of conditionality. If recipients just cover sunk costs, projects go forward. If they fall just short, donors shut projects down.

If donors break out of current proliferation patterns, they may be able to raise development impact in countries suffering from proliferation if there are scale economies to be exploited. Descending somewhat from the abstract world of the model, the key may be for donors to emphasize sectors where scale economies are more likely.

Scholarly examination of aid project proliferation, like the economics of aid administration generally, is in its infancy. Concern about the extent of project proliferation, especially in low-income 'donor darlings', is itself proliferating while the body of sharp theoretical and empirical analysis has not kept up. Since this paper is primarily theoretical, its main value may lie in its offering a mathematical paradigm. The aid process is conceived of as a set of production activities, lognormally distributed by size, each taking inputs from both donor and recipient. The complexity arises from differences in the production functions for two outputs and the differences in utility functions of the two agents. 
The paper could serve as a point of departure for additional theory as well as empirical research. Potential future directions in the theory include introducing alternative production functions, endogenizing donor behaviour, allowing multiple donors, modelling interactions between projects, and repeated game aspects. Meanwhile, the models generate empirical questions. How great are sunk costs, and how do they vary with project size? How are aid projects best represented as production functions? Perhaps a more flexible form such as constant-elasticity-of-substitution functions is needed. Are recipient or donor resources the dominant factors in aid project production? How is the recipient resource $R$ best thought of? Can it be measured? How does it vary by country? When do recipients refuse to invest resources in aid projects even at the expense of their termination?

This last question is particularly important because in the model the sharp drop in the marginal effectiveness of aid occurs at the point where it becomes optimal for development for the recipient to de-fund substantial numbers of projects - and yet does not. The model predicts that as aid continues to rise, it will eventually reach the point where the recipient does de-fund projects. The more developmentalist the recipient, the less will donors need to overshoot the point of diminishing returns before the recipient does begin to de-fund projects.

Especially in an international context where donors are contemplating a double or tripling of aid to Africa, it is crucial for donors to be sensitive to signs, such as in Tanzania, that relatively developmentalist recipients are resisting the proliferation of projects and the associated administrative burden. While donors' desire for monitoring and accountability is understandable, in recipient countries with limited budgets, pushing these desires too hard can push the aid delivery process against structural limits and undermine overall effectiveness. In such countries donors should therefore contemplate varying the parameters within their control, funding fewer, larger aid activities. That in turn may call for careful analysis of which sectors offer the great scale economies for aid projects.

\section{References}

Acharya, A., A. de Lima, and M. Moore (2004). 'Aid Proliferation: How Responsible are the Donors?'. Working Paper No. 214. Brighton: Institute for Development Studies.

ActionAid International (2005). Real Aid: An Agenda for Making Aid Work. London: ActionAid.

Aitchison, J., and J. A. C. Brown (1963). The Lognormal Distribution. Cambridge: Cambridge University Press.

Chiang, A. C. (1992). Elements of Dynamic Optimization. New York: McGraw-Hill.

Clemens, M., and S. Radelet (2003). 'The Millennium Challenge Account: How Much Is too Much, How Long Is Long Enough?'. Working Paper No. 23. Washington, DC: Center for Global Development. 
Clemens, M. A., and T. J. Moss (2005). 'Ghost of 0.7\%: Origins and Relevance of the International Aid Target'. Working Paper No. 68. Washington, DC: Center for Global Development.

Clemens, M., S. Radelet, and R. Bhavnani (2004). 'Counting Chickens when They Hatch: The Short Term Effect of Aid on Growth'. Working Paper No. 44. Washington, DC: Center for Global Development.

Collier, P., and D. Dollar (2002). 'Aid Allocation and Poverty Reduction'. European Economic Review, 45 (1): 1-26.

Development Assistance Committee (DAC) (2002). Reporting Directives for the Creditor Reporting System. Paris: OECD-DAC.

DAC (2005). Development Assistance Committee Online. Paris: OECD.

Dalgaard, C., H. Hansen, and F. Tarp (2002). 'On the Empirics of Foreign Aid and Growth'. Working Paper No. 02/08. Nottingham: Centre for Research in Economic Development and International Trade, University of Nottingham.

Durbarry, R., N. Gemmell, and D. Greenaway (1998). 'New Evidence on the Impact of Foreign Aid on Economic Growth'. Working Paper No. 98/08. Nottingham: Centre for Research in Economic Development and International Trade, University of Nottingham.

Hadjimichael, M. T., D. Ghura, M. Muhleisen, R. Nord, and E. M. Ucer (1995). 'SubSaharan Africa: Growth, Savings, and Investment, 1986-93'. Occasional Paper No. 118. Washington, DC: International Monetary Fund.

Hansen, H. (2001). 'The Impact of Aid and External Debt on Growth and Investment: Insights from Cross-Country Regression Analysis'. Paper presented at WIDER Conference on Debt Relief, 17-18 August, Helsinki.

Hansen, H., and F. Tarp (2000). 'Aid Effectiveness Disputed'. Journal of International Development, 12 (3): 375-98.

Hansen, H., and F. Tarp (2001). 'Aid and Growth Regressions'. Journal of Development Economics, 64 (2): 547-70.

Morss, E. R. (1984). 'Institutional Destruction Resulting from Donor and Project Proliferation in Sub-Saharan African Countries'. World Development, 12 (4): 465-70.

Knack, S., and A. Rahman (2004). 'Donor Fragmentation and Bureaucratic Qualityin Aid Recipients'. WB Policy Research Working Paper 3186. Washington, DC: World Bank.

Lensink, R., and H. White (2001). 'Are There Negative Returns to Aid?' Journal of Development Studies, 37 (6): 42-65.

Press, W. H., B. P. Flannery, S. A. Teukolsky, and W. T. Vetterling (1988). Numerical Recipes in C: The Art of Scientific Computing. Cambridge: Cambridge University Press.

Roodman, D. (2005). 'An Index of Donor Performance'. Working Paper No. 67. Washington, DC: Center for Global Development. 
UN Development Programme (2005a). Human Development Report 2005: International Cooperation at a Crossroads: Aid, Trade and Security in an Unequal World. New York; United Nations.

UN Development Programme (2005b). Investing in Development: A Practical Plan to Achieve the Millennium Development Goals. London: Earthscan.

Van de Walle, N., and T. A. Johnston (1996). 'Improving Aid to Africa'. Policy Essay No. 11. Washington, DC: Overseas Development Council.

Varian, H. R. (1992). Microeconomic Analysis, 3rd edition. New York: W.W. Norton.

World Bank (2005). Global Monitoring Report 2005: Millennium Development Goals: From Consensus to Momentum. Washington, DC: World Bank. 